Personality Traits and Personal Values: A Meta-Analysis

\author{
Laura Parks-Leduc \\ Department of Management \\ James Madison University \\ 800 S. Main St., MSC 0205 \\ Harrisonburg, VA 22807 USA \\ leduclm@jmu.edu \\ Gilad Feldman \\ Department of Management \\ Hong Kong University of Science and Technology \\ Clearwater Bay, Kowloon, 999077 \\ Hong Kong SAR \\ filian@ust.hk \\ Anat Bardi \\ Department of Psychology \\ Royal Holloway University of London \\ Egham \\ Surrey, TW20 0EX \\ United Kingdom \\ Anat.Bardi@rhul.ac.uk
}

Running head: Traits \& Values Meta-Analysis

To appear in Personality and Social Psychology Review

Author Note: The authors wish to thank Frank Schmidt and In-Sue Oh for their feedback on various meta-analytic issues we faced in developing this manuscript. 


\begin{abstract}
Personality traits and personal values are important psychological characteristics, serving as important predictors of many outcomes. Yet, they are frequently studied separately, leaving the field with a limited understanding of their relationships. We review existing perspectives regarding the nature of the relationships between traits and values and provide a conceptual underpinning for understanding the strength of these relationships. Using 60 studies, we present a meta-analysis of the relationships between the Five Factor Model (FFM) of personality traits and the Schwartz (1992) values, and demonstrate consistent and theoretically-meaningful relationships. However, these relationships were not generally large, demonstrating that traits and values are distinct constructs. We find support for our premise that more cognitively-based traits are more strongly related to values and more emotionally-based traits are less strongly related to values. Findings also suggest that controlling for personal scale-use tendencies in values is advisable.
\end{abstract}

Keywords: personality traits, personal values, meta-analysis 
Personality Traits and Personal Values: A Meta-Analysis

Advancing an integrative view of the person is a major goal in current personality research (see Barenbaum \& Winter, 2008; Cervone, 2005; McAdams \& Pals, 2006; Sheldon, 2004). Although personality traits have often been viewed as central to the understanding of the person, the position of personal values has generally been more peripheral (see, e.g., Bilsky \& Schwartz, 1994; Buss, 1989; Hofstee, 1994). Some personality scholars have suggested the inclusion of values in an integrative model of characteristics of the individual (McAdams, 1996; McClelland, 1996; Shoda \& Mischel, 2006; Winter, John, Stewart, Klohnen, and Duncan, 1998), yet little theoretical or empirical work has been developed to accomplish this goal (Schwartz, 2011a). If traits and values are to be combined into a unified model, a starting point is to examine empirical links between personality traits and personal values.

In this paper, we review and clarify conceptual issues regarding proposed models of relationships between personality traits and values, and use meta-analysis to summarize past findings regarding these relationships in order to advance a more integrative understanding of the person. We make the following contributions to the literature: First, we clarify definitions and describe various views on the nature of the relationships between traits and values. Second, we propose a conceptual underpinning for understanding which traits should have stronger relationships with values and why; and third, we offer empirical support for the distinction between traits and values and explore their interrelations using meta-analysis. We position our discussion and analyses within the context of the most researched models of traits and values, the Big Five (or Five Factor) model and Schwartz’s (1992) Value Theory (respectively). 


\section{Personality Traits and Personal Values}

Personality traits are typically defined as descriptions of people in terms of relatively stable patterns of behavior, thoughts, and emotions (e.g., McCrae \& Costa, 2003). The Five Factor Model (FFM) is the most researched taxonomy of traits worldwide (e.g., Allik, 2005; McCrae \& Costa, 1997); within this model, a large number of traits are combined into five broad trait dimensions that load onto orthogonal factors. The factors and descriptive traits for each are provided in Table 1.

Personal values (e.g., achievement, security) are generally described as rather stable broad life goals that are important to people in their lives and guide their perception, judgments, and behavior (e.g., Rokeach, 1973; Schwartz, 1992). Values are organized in personal hierarchies of importance, so that different people consider some values as more important than others. The most widely used model of values is the Schwartz (1992) Value Theory, which identifies ten broad values based on the motivations underlying them. Descriptions of these values are provided in Table 2.

According to Schwartz’s theory and ample empirical evidence, values are structured in a circle based on their interrelationships, such that values that are more positively correlated are closer to one another and are thought to be based on compatible motivations (see Figure 1). For example, both self-direction and stimulation values are based on the motivation for novelty and are therefore positively correlated and adjacent to one another in the value circle. Values that emanate from opposite sides of the circle are negatively correlated and are thought to be based on conflicting motivations. For example, self-direction values stem from the motivation for independent thought and action which conflicts with the motivation to fulfill others’ expectations, the latter underlying conformity values. The 10 values can be further grouped into 
four higher-order types of values organized on two bipolar dimensions: self-enhancement vs. self-transcendence, and openness to change vs. conservation (see Figure 1). This values structure has been examined in over 75 countries worldwide and has been found to be largely universal (Schwartz, 2011b).

Although traits and values are conceptually similar, researchers describe several distinctions between the two constructs (for reviews see Bilsky \& Schwartz, 1994; Hitlin \& Piliavin, 2004; Parks \& Guay, 2009). The most basic difference between traits and values is that traits are descriptive variables whereas values are motivational variables. That is, traits describe how individuals tend to feel, think, and behave. They are therefore summaries of an individual's responses and behaviors. Unlike traits, values express a person's motivations which may or may not be reflected in behavior (Roccas, Sagiv, Schwartz, \& Knafo, 2002). For example, a creative person (trait) tends to engage in creative thinking and in creative acts, otherwise this person would not be labeled as having the trait of creativity. But valuing creativity may or may not result in creative thinking or behavior. Valuing creativity means that the person would like to be creative and thinks that creativity is important, whether or not he or she acts on this value. Hence, although it makes sense to expect that most creative people will view creativity as important in their lives, the trait and the value are not identical, and people can have different scores on a trait and a value that share similar content.

Many researchers (e.g., Olver \& Mooradian, 2003) also propose the distinction that traits are more biologically based (Goldberg, 1993; McCrae \& Costa, e.g. 2008), while values are more of a product of a person's environment, including culture, education, parental upbringing, and life events (Rokeach, 1973). We believe that this theoretical distinction has some merit, though it is most likely an oversimplification, and additional research is needed to test the 
accuracy of this claim. While traits are known to be influenced by genetics, they do vary somewhat by culture and are influenced by environmental variables in addition to genetics (e.g., Heine \& Buchtel, 2009; Kandler, 2012). Additionally, research on heritability suggests that values have genetic origins in addition to environmental ones (Knafo \& Spinath, 2011; Schermer, Vernon, Maio, \& Jang, 2011). Understanding the relationships between traits and values has the potential to add clarity to continued research in this area.

\section{The Nature of the Relationships between Traits and Values}

Researchers differ in the way they view the nature of the relationships between traits and values. They also differ on how they believe traits and values fit within the overall conceptualization of characteristics of the individual (which is often broadly termed “personality,” even when it includes characteristics beyond traits). Although both traits and values share a common heritage in the lexical hypothesis (the idea that all important descriptors of an individual will be encoded in language, and can therefore be culled from a dictionary), the two constructs have been examined separately since at least the 1930s, when Allport (1937) took pains to remove values items from his research studies on personality. He referred to traits as temperament, and values as character (Allport, 1937); these descriptors resurface at times (see, for example, Cloninger, 1994), but it is not always clear whether the term “personality” is a reference to temperament only, or to both temperament (traits) and character (values).

Some researchers do not make the distinction between personality traits and personal values, using the terms largely interchangeably (e.g., Lee \& Ashton, 2004). In contrast, others view traits and values as entirely separate constructs that exist at the same level of abstraction and prediction; these theorists tend to view psychological needs as antecedents to both (e.g., 
Parks \& Guay, 2009; Roccas et al., 2002). They also tend to define personality as the aggregate of traits only (not values).

Other researchers view traits and values as different components of personality (e.g., Caprara, Alessandri, \& Eisenberg, 2012; Saroglou \& Munoz-Garcia, 2008), drawing on two integrative models of personality. The first model suggests three levels of personality components, differing in their level of contextualization (McAdams, 1995; see also Sheldon, 2004, for a broader variation of this model). In this model, traits are located in the first level as non-contextualized components of personality, whereas values are part of the second level of more contextualized elements of personality (the third level has to do with one's life narratives and personal identity; McAdams, 1995).

The second integrative model suggests that traits are basic tendencies that have a biological basis and that traits influence characteristic adaptations, which include values (McCrae \& Costa, e.g., 2008). In this model, values are influenced both by traits and by external influences, such as culture and life events. Thus, values are influenced by traits but not solely determined by them. To illustrate, if an individual is naturally creative (trait), he or she might also value creativity as an important life goal to pursue. But this relationship is not deterministic -- a person might value creativity even if he or she is not creative, perhaps as a result of culture or upbringing.

Neither of the integrative models suggest any reason to expect strong links between the levels of personality (i.e., McAdams, 1995; McCrae \& Costa, e.g., 2008). Therefore, if traits and values are related, the relationships are not likely to be particularly strong. These models also both view traits as antecedent to values (see also Wijnen, Vermeir, \& Kenhove, 2007). Yet, values might also influence traits (Roccas et al., 2002). Specifically, as values motivate 
behavior, if a value (e.g., benevolence) leads to recurrent behavior (e.g., caring for one’s younger siblings), this recurrent behavior will later become a trait, because traits include recurrent patterns of behaviors.

To summarize, some researchers do not clearly distinguish between traits and values, some view them as distinct and separate constructs, and some view them as loosely related components at different levels of personality. This myriad of views, and the confusion it creates in the literature, needs to be acknowledged. As meta-analysis relies on correlations, we do not attempt to provide explanations regarding the direction of relationships or superiority of one model over the others. However, before integrating traits and values into a comprehensive understanding of the individual, establishing the patterns and magnitudes of these relationships is an important first step.

\section{Two Sources for the Strength of the Relationships between Traits and Values}

Although the links between traits and values are not expected to be strong, some of the traits of the Five Factor Model (FFM) may be more closely related to values than are others, as found in previous research. Although researchers have developed hypotheses for these relationships based strictly on content similarity, we propose that the strength of the relationships between traits and values may be based on two sources of similarities - similarities in the nature of particular traits and values and similarities in the content of particular traits and values.

Similarities in the nature of traits and values. All values are inherently cognitive (see, e.g., Schwartz \& Bilsky, 1987). Yet unlike values, traits may vary in the extent to which they are based on cognition (recall that traits are described as recurrent patterns of thought, behavior and affect; McCrae \& Costa, 2003). Supporting the stronger cognitive nature of values compared to traits, Roccas et al. (2002) found that values predicted a cognitively-based outcome better than 
traits, and traits predicted an affectively-based outcome better than values. We expect that traits that are more cognitive in nature will tend to have stronger relationships with values, because values are cognitive in nature. In contrast, values are not emotional variables - although they can elicit negative emotions when they are violated, or positive emotions when fulfilled (Locke, 1997; Schwartz, 1992; Sheldon \& Elliott, 1999). We therefore expect weaker correlations with values for traits that have a large emotional component.

Which traits in the FFM are the most cognitive and which ones are the most affective? Using judges’ ratings of items from multiple Big Five inventories, Pytlik Zillig and colleagues (Pytlik Zillig, Hemenover, \& Dienstbier, 2002) found that openness to experience had a consistently strong cognitive component, and emotional stability had a strong affective component. The remaining three traits were all described primarily by behavioral items (defined as overt, directly observable actions). This finding suggests that openness to experience should have the strongest relationships with relevant values, whereas emotional stability should have the weakest. The remaining three traits should fall in between. Note that while extraversion is often defined as an affective trait, the typical measurement of extraversion is primarily in behavioral rather than affective terms, so we do not expect it to be similar to emotional stability in its relationships with values.

Additional support for this premise comes from research that examines the neuroscience of personality. Cloninger (1994) developed a personality taxonomy that includes seven major personality traits based on the different neurobiological processes that occur in the brain during trait expression. He retained Allport's terms of temperament and character as separate components of personality, and defined temperament as “automatic associative responses to emotional stimuli that determine habits and moods, whereas character refers to the self-aware 
concepts that influence our voluntary intentions” (p. 266). The temperament traits relate to emotional and automatic processes - activities that are primarily associated with the mid-brain. The character traits involve the frontal lobe (frontal cortex) to a greater degree than the temperament traits, suggesting that the character traits are linked to higher levels of cognitive processing. Neurobiological research therefore supports the premise that traits vary in terms of the extent to which they are affectively- or cognitively-based. In a subsequent study, De Fruyt and colleagues (De Fruyt, Van De Wiele, \& Van Heeringen, 2000) correlated Cloninger's traits with the Big Five. They found that emotional stability (neuroticism in their study) was strongly correlated with one of Cloninger's temperament traits (mid-brain), supporting our expectations for a weak correlation for emotional stability with values. Openness to experience, extraversion, and conscientiousness all exhibited moderate positive correlations with both temperament and character traits, whereas agreeableness showed a strong positive correlation only with a character trait (frontal lobe), leading us to expect relatively strong links for agreeableness with values.

In summary, the FFM traits vary in the extent to which they are cognitively-oriented, based on both research on the item-level content of Big Five traits and research on the neurobiological processes involved in personality expression. Taken together, we expect that openness to experience should have the strongest links with values, followed by agreeableness. Emotional stability should have the weakest links with values, and conscientiousness and extraversion should fall somewhere in between.

Similarities in the content of traits and values. As research has demonstrated, the strength of relations between traits and values should also be somewhat determined by content similarity when comparing each trait to each value. We briefly review previously hypotheses 
for expected links between traits and values, focusing on links that have been hypothesized by at least two of these previous papers.

Openness to Experience. As stated above, we expect openness to experience to have the strongest and most coherent patterns of relations with values, as compared to the other traits in the FFM. The content of this trait dimension is quite similar to the bipolar higher-order value dimension of openness to change vs. conservation (see Figure 1), which contrasts openness to new ideas and experiences with a preference for rigid rules of actions and thoughts (Rohan, 2000). Hence, individuals who score highly on openness to experience are likely to value stimulation and self-direction and to ascribe low importance to conformity, tradition, and security values (Luk \& Bond, 1993; Olver \& Mooradian, 2003; Roccas et al., 2002). In particular, we expect the relationship between openness to experience and self-direction to be particularly strong, as both relate to curiosity and creativity. Individuals who score highly on openness to experience are also likely to value universalism, as universalism values include tolerance and openness to ideas and behaviors that are different from what one is accustomed to (Olver \& Mooradian, 2003; Roccas et al., 2002; see also Schwartz, 1992). To summarize, we expect openness to experience to exhibit relationships with the following values: stimulation $(+)$, self-direction (+), universalism (+), conformity (-), tradition (-) and security (-).

Agreeableness. Agreeable individuals are oriented toward helping others and cooperating with them (e.g., Graziano \& Eisenberg, 1997; John \& Srivastava, 1999). This orientation is similar to the motivation underlying benevolence values, which aims to enhance the well-being of people in one’s immediate social environment (family, friends, etc.). Cooperation with others requires some willingness to adapt to group norms as well. Conformity values express the motivation to fulfill the expectations of others in one's social groups. 
Similarly, tradition values express the motivation to maintain the customs, traditions, and hierarchy of one’s social groups. Therefore, both conformity and tradition are likely to be positively related to the cooperative aspect of agreeableness (Luk \& Bond, 1993; Olver \& Mooradian, 2003; Roccas et al., 2002). In contrast, power values express the motivation for dominance and control, sometimes at the expense of others. They are therefore incongruent with agreeableness (Olver \& Mooradian, 2003; Roccas et al., 2002). We thus expect agreeableness to exhibit relationships with the following values: benevolence $(+)$, conformity $(+)$, tradition $(+)$, and power (-).

Extraversion. Extraverts need stimulation. They are highly energetic, ambitious, assertive, and reward-seeking (e.g., Costa \& McCrae, 1992; John \& Srivastava, 1999). This tendency to seek rewards and to be ambitious is highly compatible with achievement values (Luk \& Bond, 1993; Roccas et al., 2002). In addition, being energetic and having a high need for stimulation is highly compatible with stimulation values (Bilsky \& Schwartz, 1994; Luk \& Bond, 1993; Roccas et al., 2002). We therefore expect extraversion to be related to achievement $(+)$ and stimulation $(+)$ values.

Conscientiousness. This trait dimension describes socially prescribed impulse control that facilitates task and goal-directed behavior (e.g., Fiske, 1994; Hogan \& Ones, 1997; John \& Srivastava, 1999). McCrae and John (1992) suggested that conscientiousness has two major components, each compatible with different values. The first is a proactive aspect of conscientiousness, which is related to the motivation for success according to social standards (Costa \& McCrae, 1988). This motivation is also expressed in achievement values (Luk \& Bond, 1993; Roccas et al., 2002). The second aspect of conscientiousness is inhibitive and is related to the motivation for impulse control (Costa \& McCrae, 1988), expressed in conformity 
values (Olver \& Mooradian, 2003; Roccas et al., 2002). Hence, conscientiousness should be related to achievement $(+)$ and conformity $(+)$ values.

Emotional Stability. People who score highly on this trait tend to be less prone to negative affect (Costa \& McCrae, 1988; John \& Srivastava, 1999). They are not easily distressed and have healthy coping strategies (Gunthert, Lawrence \& Armeli, 1999). As this trait is primarily affective, and as values do not tend to have direct relations to well-being or distress (Roccas et al., 2002; Sagiv, Roccas, \& Hazan, 2004), this trait is likely to be unrelated to values. Sinusoid Patterns of Correlations

According to values theory (Schwartz, 1992; 1996), if theory predicts that a certain variable (such as religiosity) is associated with a certain value (such as tradition), this variable should also exhibit positive relations with compatible types of values (those that are adjacent to it on the circle; in this example conformity, security, and benevolence) and negative relations with conflicting types of values (those that are opposite to it on the circle; in this example hedonism and stimulation). Because the value circle is based on a motivational continuum, related variables should have a systematic pattern of correlations with the entire value system. The variable of interest should be most positively related to the value that is most clearly positively linked with it, and the correlations should become less and less positive as one moves around the circle and away from that value, eventually moving to negative relationships. The negative relationships should reach their maximum with the value on the circle that directly opposes the value with the strongest positive correlation. If one graphs the correlations, with the values provided on the graph from left to right in order as one moves clockwise around the circle, the subsequent line should form a sinusoid curve (a sine wave, with one major peak and one major valley). 
We expect openness to experience, agreeableness, and extraversion to display a sinusoidal pattern of correlations with the full set of values. Specifically, the highest positive correlation should be with the corresponding value according to the research reviewed above, and the correlations with other values should decrease monotonically going around the circle of values, creating a sinusoid shape. We do not expect this pattern with conscientiousness, because it should be most positively related to two non-adjacent values (achievement and conformity).

\section{Possible Moderators}

What might affect the strength of relations between traits and values? We consider five moderators, starting with moderators based on theoretical considerations followed by moderators based on methodological issues.

Culture. Culture is often defined as a shared system of meaning (e.g., Smith \& Bond, 1998), and cultures differ in the meanings they attribute to events. Different cultures may result in different trait-value relations. Of the possible cultural dimensions that one could consider, individualism versus collectivism and tightness versus looseness seem to have the potential to moderate the relationships between traits and values.

Individualism versus collectivism is the most studied cultural dimension (Taras, Kirkman, \& Steel, 2010). According to Hofstede (1980), individualistic cultures emphasize individuality -- the uniqueness of the individual and his or her right to pursue personal goals. In contrast, collectivistic cultures emphasize the importance of one's group and, as a result, the obligations to one's group. Cultures also differ in strength -- in the pervasiveness of social norms and in the tolerance to deviant behavior from those norms (Pelto, 1968). Tight societies have a culture with very strong norms and severe sanctions for the violation of those norms, whereas loose cultures have more ambiguous norms and are more permissive of possible deviance 
(Gelfand, Nishii, \& Raver, 2006; Gelfand et al., 2011). Cultures that are tighter or more collectivistic are thus likely to encourage more normative value endorsement, whereby individuals within the culture would be more likely to subscribe to the dominant values of the culture, rather than those consistent with the individual's traits. In contrast, members of looser cultures or more individualistic cultures might be more likely to endorse values that are consistent with their individual personality traits, leading to higher correlations between values and traits in more individualistic or looser cultures (for a similar argument regarding the links between values and behavior, see Roccas \& Sagiv, 2010).

Alternatively, the relationships between traits and values may be universal as they may stem from the same psychological processes across cultures. Indeed, although ample research demonstrates that the means of measures of values and traits vary cross-culturally (see, e.g., Allik, 2012 regarding traits; Schwartz, 2011b regarding values), the links between the two systems may be universal, just as the intercorrelations among traits and those among values are largely universal (see, e.g., McCrae \& Costa, 1997; Schwartz, 2011b). Finding that these relationships are universal would support the view that the links between traits and values are based on processes that are largely unaffected by culture. This moderator analysis is therefore particularly interesting, as its results may inform our fundamental understanding of the relationships between traits and values.

Values instruments. Traits and values have been measured by different instruments, which makes results difficult to generalize because differences across studies may be the result of using different scales that assess traits or values in a somewhat different fashion. However, the variety of scales used, particularly for traits, meant that few studies used the same measures. As a result, we could not conduct fully hierarchical moderator analyses considering both the 
traits measure and the values measure. For values, however, most studies used one of two instruments: the Schwartz Value Survey (SVS; Schwartz, 1992) or the Portrait Values Questionnaire (PVQ; Schwartz, Melech, Lehmann, Burgess, Harris, \& Owens, 2001). We therefore conducted a basic moderator analysis using the values instrument as a moderator.

The PVQ was developed from the SVS with the intention of creating an instrument that was less abstract and less cognitively complex. Rather than rating the importance of each value, respondents read descriptions of individuals (i.e., portraits) in terms of values and rate the extent to which the described person is similar to them. An important difference between these instruments for the purposes of the current investigation involves how directly they measure values. The SVS measures values directly, because participants rate abstract goals in terms of how important they are as a guiding principle in their lives. Unlike the SVS, in the PVQ participants read a description of a person and rate how similar that person is to them. The description of the person includes two sentences. Often, one sentence describes the person in terms of a goal that is important to him or her. This is a direct measure of a value. For example, the first part of an item that measures security values is "It is important to her to live in secure surroundings." Yet the other sentence sometimes involves trait-like elements. For example, the second sentence of the item above is "She avoids anything that might endanger her safety.” As the PVQ has trait-like elements, it is likely to result in inflated trait-value correlations compared with the SVS.

Personality instruments. Although 11 personality instruments were utilized in the studies that we examine, two were used frequently enough to include them in a moderator analysis: the NEO (Costa \& McCrae, 1992) and the Big Five Inventory (BFI; John, Donahue, \& Kentle, 1991). Arguably the best-validated of personality inventories, the NEO is commercially 
available with differing versions based on age and gender, and it is widely used in a variety of settings (John \& Srivastava, 1999). McCrae and Costa developed the NEO (Neuroticism, Extraversion, and Openness to Experience) initially from the work of previous personality researchers, most notably Cattell. They later added Agreeableness and Conscientiousness, creating the NEO-PI-R. This inventory provides 240 items measuring 6 facets each for each of the 5 factors. Items are provided in sentence form, with participants rating their level of agreement (or disagreement). McCrae and Costa subsequently developed a short version (60 items; the NEO-FFI) that only assesses the 5 factor-level constructs. Although it is not identical, the NEO-PI-R and the NEO-FFI are substantially correlated (John \& Srivastava, 1999), hence we group them together in our moderator analysis.

Researchers developed the BFI (John et al., 1991) in an effort to achieve some convergence among differing views of the content of the factors of the Big Five, which were conceptualized somewhat differently by different researchers. Ten judges with psychology backgrounds reviewed the literature on all the existing versions of the Big Five, and the categorized 300 items from the Adjective Check List (ACL) into five categories. The researchers then retained the items for which there was a high level of agreement, and from there, culled the list down to 44 representative items. Because adjectives can sometimes have more than one meaning, they created short phrases for items (John \& Srivastava, 1999). The BFI and the NEO are highly correlated but not exactly the same; corrected correlations range from .83 (Extraversion) to .97 (Agreeableness) (John \& Srivastava, 1999). Because the NEO and the BFI are highly correlated and because both rely on longer descriptions (sentences or phrases), we expect them to yield fairly similar results. 
Statistical adjustments for values scale use. Values research requires a somewhat different approach to data analysis compared to traits. People make decisions about how to behave not based on the absolute importance of a value but rather on its importance relative to other values. In other words, we cannot predict behavior based solely on how high a person's score is on benevolence values; we need to know how high it is relative to other values that the person also endorses. Moreover, individuals differ in their use of the scale such that some people tend to attribute high importance to values across items, and some low. Schwartz (1992) therefore recommended controlling for mean importance of values. Due to these theoretical reasons, we anticipate that the expected trait-value relations will be more accurate when scaleuse tendency of values is controlled. While the majority of studies controlled for scale use in the correlation matrix, some reported only the zero-order correlations (in some cases these studies subsequently controlled for scale use in their regression equations or path estimates, which would typically be viewed as more critical to hypothesis testing).

Other moderators. Many studies are conducted with university students, who are a more homogeneous group than the general population, and can therefore generate somewhat different results in studies compared to the general population (Peterson, 2001). We therefore examined study population as a potential moderator. Because the studies included varied greatly in sample size, we also tested whether sample size moderates trait-value correlations. Finally, as is often done in meta-analyses, we tested whether publication status moderates trait-value relations to account for a possible publication bias. 


\section{Meta-analytic Methods}

\section{Literature Search}

To locate articles for inclusion we conducted searches using major electronic databases such as PsycINFO. We used the keywords "personality," "traits," and "values” to search for related articles. We additionally scanned the reference sections from the articles produced by the initial search to see if additional studies could be located in this fashion. For studies located that did not include correlations tables, we contacted authors to request their raw data. Finally, we contacted researchers in this domain to request unpublished studies and posted requests for data on related list serves. Studies were collected up until April of 2013; the search yielded 88 possible studies.

Inclusion criteria. We restricted our meta-analysis to the dominant taxonomies for categorizing traits and values reviewed above - the FFM and the Schwartz values theory (see Tables 1 and 2), and to those studies that examined traits and values at the individual (rather than group) level. One study (Wijnen, Vermeir, \& Van Kenhove, 2007) divided openness to experience into two facets, labeled "self-rated intelligence” and “creativity.” Correlations were averaged across these facets to create a factor-level correlation for the meta-analysis. One study (von Collani \& Grumm, 2009) grouped values into 4 broader categories rather than using the 10 value types; it was eliminated from our study (results of analyses for the 4 higher-order value dimensions are available in supplementary files).

Some studies were excluded because they did not provide the necessary quantitative data for a meta-analysis. Specifically, eight studies did not include a correlation matrix (and we were unable to obtain a correlation matrix from the author[s]); two studies included only significant correlations; and one study used canonical correlations. These were excluded. This yielded a 
total of 60 studies (listed in Table 3), including 29 from published articles, 1 book chapter, 25 unpublished data sets, two data sets from conference presentations, and three samples from dissertations. Several studies had very large sample sizes; 10 studies had samples of more than 1,000 participants. The largest four data sets were data gathered from web sites and social networks - MyType (N=15,805; Wilson, Gosling, \& Graham, 2012), YourMorals.org (N=7,543; Graham et al., 2011), and two from myPersonality.org (N=2,986 and 1,487; Kosinski \& Stillwell, 2011). Both myType.com and myPersonality.org can be accessed from Facebook, and include a variety of surveys designed to tell people more about themselves, including a MyersBriggs test, a Big Five personality traits test, the Schwartz Value Survey, and others. myType.com surveys have been taken by over 17,000 users. YourMorals.org is a site developed by social psychologists to enhance the study of various topics related to moral, social, and political psychology; it also includes a variety of surveys, including a Big Five measure and the Schwartz Value Survey (Graham, Haidt, \& Nosek, 2009; Graham et al., 2011).

Meta-analysis procedure. Meta-analytic procedures were based on Hunter and Schmidt (2004). We corrected correlations for unreliability and sampling error (SPSS syntax adopted from Field \& Gillett, 2010). Two studies collected data on traits or values using more than one scale. This yielded two correlations that were not independent (because they came from the same respondents). For one of these studies (Bardi \& John, 2006), composite correlations were calculated before inclusion in the meta-analysis. Composites were calculated based on formulas provided by Hunter and Schmidt (2004). Because composite calculations require that intercorrelations between all scales be provided, we were unable to perform the same procedure for the other study (Olver \& Mooradian, 2003). For this study, therefore, the average correlations were calculated and these were included instead. 
Most studies reported coefficient alpha reliabilities, but a few did not. When possible, correlations were corrected individually. When reliability estimates were not provided, artifact distribution was used to provide a mean reliability; this was then used to correct for unreliability (see Table 4 for average reliabilities). None of the studies reported reliability estimates accounting for transient error, and as a result they are likely to overestimate the true reliability of the scales. No corrections were made for range restriction, as data were not available to calculate range restriction on values. Past research on traits has found little evidence of range restriction, however, and the same is likely to be true of values.

Moderator analyses. Hunter and Schmidt (2004) recommend hierarchical moderator analyses when a sufficient number of studies exists. If moderators are related and the analyses are not hierarchical, failing to conduct hierarchical moderator analyses can lead to false conclusions (i.e., moderation could be attributed to the wrong construct). However, the number of studies was insufficient to perform hierarchical moderator analyses considering all moderators. As a result, we conducted separate moderator analyses for each of the moderators, but we are cautious in our conclusions. Our cultural moderators were modeled as continuous variables; all other moderators were categorical.

Culture. The primary studies included in the meta-analysis were conducted in 13 countries in North America, Europe, and Asia. This provided cross-cultural variability that enabled us to consider whether cultural differences could create a moderator effect, i.e., whether trait-value relationships might vary by culture. Several studies were conducted across multiple countries and cultures; these were removed from this set of analyses.

To conduct the individualism/collectivism moderator analysis, studies were assigned a number representing their level of individualism vs. collectivism, based on data from Hofstede 
(1980; for previous use of this method see Bardi \& Guerra, 2011; Suh, Diener, Oishi, \& Triandis, 1998). Based on his empirical data, Hofstede assigned culture scores ranging from 1-100, with 1 representing very high collectivism and 100 indicating very high individualism. For example, the United States is very individualistic and has a score of 91 . Spain has a score of 51, about the middle of the scale. Hong Kong, with a much more collectivist culture, has a score of 25. Our studies were skewed toward the high end of the scale; the majority of the studies were conducted in countries with moderate to high individualism scores. Because this moderator was modeled as a continuous variable, weighted least squares (WLS) regression was used for the moderator analysis rather than sub-grouping, as recommended by Steel and Kammeyer-Mueller (2002). With WLS regression, the correlation is considered the dependent variable, and the moderator the independent variable, in a regression analysis (with each study weighted by the inverse of the sample error variance). Significant betas indicate that moderation has occurred.

To examine the tightness/looseness of culture as a moderator, studies were assigned a tightness score based on data from Gelfand and colleagues (Gelfand et al., 2011), with higher scores representing a tighter culture. For example, Turkey had a relatively high score of 9.2, representing strong cultural norms. Israel, in contrast, scored a 3.1, suggesting more acceptance of behavior that is inconsistent with cultural norms. Included studies were fairly normally distributed in terms of this cultural moderator; most were in the middle, while a few studies were at either end of the range. As in the previous analysis, WLS regression was used to conduct the moderator analysis.

Values instruments. The SVS has a list of 56 (Schwartz, 1992) or 57 (Schwartz, Sagiv, \& Boehnke, 2000) value items (e.g., social power, daring) that participants rate as a guiding principle in their own life on a 9-point scale, from -1 (opposed to my principles) to 0 (not 
important) to 7 (of supreme importance). The scale is asymmetric to capture discriminations between values, as all values are desirable in society (Schwartz \& Bardi, 2001). Rather than rating the importance of each value, respondents to the PVQ (Schwartz et al., 2001) read twosentence descriptions of individuals (i.e., portraits) in terms of values and rate the extent to which the described person is similar to them. There are two versions of the questionnaire - one for males and one for females - to allow for gender-specific pronouns. Sample items include "He likes to be in charge and tell others what to do. He wants people to do what he says” (power); "She looks for adventures and likes to take risks. She wants to have an exciting life" (stimulation). The PVQ includes 40 descriptive “portraits” (value items); respondents indicate how much the described person is similar to them on a 6-point scale ranging from 1 (very much like me) to 6 (not like me at all). A total of 30 studies used the SVS, and 18 used the PVQ (1 of those used the shortened, 20-item version of the PVQ, but was still included).

Personality instruments. As stated previously, 11 studies using the NEO (Costa \& McCrae, 1992) and 14 studies using the BFI (John et al., 1991) were included in this moderator analysis. The NEO includes either 240 or 60 items depending on whether or not it is examining facets. A sample item is "I am a productive person who always gets the job done" (John \& Srivastava, 1999); participants rate their level of agreement/disagreement with the statement. The BFI includes 44 short statements such as “Is original, comes up with new ideas,” for which participants utilize a 5-point scale to rate their level of agreement/disagreement in terms of how well the statement describes them.

Statistical adjustments to control for values scale use. To control for scale use tendency, researchers often partial out the overall mean score of values. Twenty-eight of the studies included in the meta-analysis clearly used a partialling method, and 22 clearly reported zero- 
order correlations (we were unable to code some studies due to missing information in the papers; these were eliminated from this analysis). Not all studies controlled for participants’ scale use tendency in the same way: the majority reported correlations after partialling out the personal mean value score, but one study subtracted the mean value score from each value domain score (Collins \& Blum, 2011), and two studies subtracted the mean value score from each value domain score and then divided that difference by the standard deviation of the scores (Dollinger, Leong, \& Ulicni, 1996). Given that they were intended to fulfill the same purpose and probably would have resulted in similar correlations, we treated these methods as sufficiently similar to group them together for the moderator analyses.

\section{Meta-Analytic Results}

\section{Individual Correlation Estimates}

Tables 5 through 9 provide the results of the main meta-analysis (one table for each trait). As expected, traits and values are related in consistent ways. Openness to experience and agreeableness, in particular, exhibit several strong relationships with values. The meta-analysis reveals that openness to experience is strongly correlated with self-direction $(\rho=.52)$; has moderate positive relationships with stimulation $(\rho=.36)$ and universalism values $(\rho=.33)$; and has a moderate negative relationship with tradition, conformity, and security values $(\rho=-.31$, .27 , and -.24 , respectively). Agreeableness relates most strongly with benevolence values ( $\rho=$

.61). It also has moderate relationships with power $(\rho=-.42)$, universalism $(\rho=.39)$, conformity $(\rho=.26)$, and tradition values $(\rho=.22)$.

Extraversion and conscientiousness exhibit fewer significant relationships (and no strong relationships) with the Schwartz value domains. Extraversion demonstrates moderate relationships with stimulation, power, achievement, and hedonism values $(\rho=.36, .31$, .31, and 
.20 , respectively). Conscientiousness is moderately related to security $(\rho=.37)$, conformity $(\rho=$ $.27)$, and achievement values $(\rho=.17)$. Finally, emotional stability did not demonstrate any significant relationships with the values domains. In total, 18 of the 50 correlations yielded generalizable relationships (those for which the $80 \%$ credibility interval around $\rho$ did not include zero; see Table 10 for a summary of these relationships). Eleven of the 50 relationships have 90\% confidence intervals (around mean $r$ ) that do not include 0 (see Table 5-9 for mean $\mathrm{r}$ and 90\% confidence intervals).

The strength of the relationships between traits and values was generally consistent with our theoretical expectations, as the more cognitively-based traits tended to have more and stronger relationships with values, and the primarily affective trait (emotional stability) was unrelated to values. The specific relationships were also largely consistent with expectations: The 14 predicted relationships all generalized, and 4 relationships generalized that we did not hypothesize (agreeableness with universalism; extraversion with power and hedonism; and conscientiousness with security). If we define "strong" relationships as those with a rho greater than .50 (see Cohen, 1988), then two of the 50 relationships are strong: agreeableness with benevolence $(\rho=.61)$, and openness to experience with self-direction $(\rho=.52)$. With only 2 strong relationships out of 50 (after correcting for statistical artifacts), traits and values are clearly distinct constructs. If we rely on the more conservative mean $r$, then none of the relationships would be classified as strong (the strongest would be agreeableness with benevolence; mean $r=.45$ ). In nearly every case, the percentage of variance accounted for by statistical artifacts was small, resulting in generally wide credibility intervals. This indicates that moderators are likely present in the data, suggesting the need for a more fine-tuned analysis of the data. 


\section{Sinusoidal Pattern of Correlations}

Schwartz $(1992,1996)$ suggested that correlations between values and any other variable should be represented graphically with a sinusoidal curve. In this type of analysis, values are listed on the horizontal axis in order (i.e., moving around the circle) and the correlations with the other variable of interest are then plotted on the vertical axis. Figures 2-6 provide plots of the meta-analytic estimates (rho) of the relationships between traits and values. With the exception of emotional stability, which does not exhibit any significant relationships with values, the pattern shows the expected sinusoid patterns as predicted by the values theory. Especially for openness to experience and agreeableness, one clear peak and one clear valley is observed such that the relationships increase and decrease monotonously as one moves around the circle. Conscientiousness, as anticipated, has two peaks. Even the weaker meta-analytic effects provide meaningful information, as they follow the sinusoidal pattern predicted by the structure of a circle, so even effects that do not generalize are interesting within the larger picture of how values relate to other variables.

\section{Moderator Analyses}

Given the volume of data involved, we present our findings in an abbreviated format in Tables 11-15. Additional data regarding moderator analyses are available from the first author.

Culture. The WLS regression results for individualism/collectivism as a moderator are summarized in Table 11. We proposed that more individualistic cultures would allow individuals greater flexibility in choosing values, such that they would be more likely to choose values consistent with their traits. Thus, we expected that trait-values relationships would be stronger in more individualistic cultures. However, only four of the 50 regression equations were significantly moderated by individualism/collectivism. The relationships for which the 
moderator effect was significant were agreeableness with hedonism, and emotional stability with achievement, stimulation, and self-direction. None of these were hypothesized to be related, and none were strong relationships in the main meta-analysis (the strongest was agreeableness with hedonism, $\rho=-.11$ ). Graphing the line resulting from each of the regression results shows that in each case the slope was positive, and that the line crosses the $\mathrm{x}$ axis (such that the relationship goes from negative to positive as the culture goes from more collectivistic to more individualistic). The results do not support our premise that the relationship between personality and values is stronger in more individualistic cultures.

We also expected that looser cultures would allow for stronger relationships between traits and values. For tightness/looseness of culture, the results (Table 12) indicate that this aspect of culture significantly moderated 7 of the 50 relationships: openness to experience with hedonism; agreeableness with universalism and security; extraversion with tradition; conscientiousness with power and universalism; and emotional stability with power. Of those seven significant effects, none were hypothesized relationships, although one relationship was moderate in strength and generalized in the main meta-analysis (agreeableness with universalism; $\rho=.39$ ). For this relationship, the slope was positive and the line did not cross zero, suggesting that as the culture gets tighter the relationship between the trait and the value gets stronger (counter to our expectations). Of the remaining six significant effects, all crossed zero. Three were negative, suggesting that as the culture became tighter, the relationships between traits and values went from positive to negative. The other three were positive, indicating that as the culture became tighter the relationships went from negative to positive. Thus the results of the tightness/looseness moderator do not suggest a consistent effect of culture on these relationships. 
In sum, none of the hypothesized relationships (from the main analyses) showed evidence of moderation in our cultural moderator analyses. Those relationships that showed evidence of cultural moderation did not provide results that were either systematic or supportive of our hypothesis. The number of studies (which ranged from 41 to 47 ) was quite modest to detect moderation using regression. With more studies, and studies from a wider range of countries, there may be greater potential for finding meaningful moderation effects by culture.

Nevertheless, the current evidence does not support the idea that culture meaningfully moderates the relationships between traits and values.

Values instruments. Results of the analyses using the value instrument (SVS or PVQ) are provided in Table 13. Credibility intervals were still generally wide, and the percent variance accounted for relatively small, after taking into account the values scale that was used. We conducted a series of z-tests to determine whether the 95\% confidence intervals overlapped when comparing the two types of studies; results indicate that 29 of the 50 relationships are significantly different between studies using the SVS vs. studies using the PVQ. Thus, the values measure appears to act as a moderator. As additional evidence, more of the relationships generalize when we separate the studies based on values measure used (that is, the credibility intervals are more narrow and less likely to include 0 ; so there is more similarity within each of the two groups of studies than there is across all studies). While 18 relationships generalized in the overall analysis, 24 relationships generalized when using just the SVS, and 24 relationships generalize when using just the PVQ. This pattern suggests that the PVQ and the SVS and not measuring entirely the same content, and researchers should bear this in mind in future research. Although the intention in developing the PVQ was to develop a measure with identical content compared to the SVS, slight differences in the coverage of content may be present. For example, 
the value item 'wisdom' from the SVS (part of universalism) is not covered in the PVQ. This is probably the value item that relates most strongly to valuing intellect, and therefore its absence from the PVQ may have weakened the relationships of the PVQ's universalism with the trait openness; indeed, the PVQ’s universalism was more weakly linked with trait openness compared with the SVS’s universalism. In general, however, as we expected, the PVQ had stronger relationships with traits than the SVS. Specifically, of the 15 hypothesized relationships, 10 were stronger with the PVQ compared to 5 that were stronger with the SVS, probably because the PVQ includes some trait-like elements in its items.

Personality instruments. Results of this moderator analysis are presented in Table 14. As with the values scales, the moderator analysis with personality scales yielded generally wide credibility intervals and results that did not account for a large percentage of variance. We again conducted a series of z-tests to determine whether the 95\% confidence intervals overlapped; results indicate that 30 of the 50 relationships are significantly different. Contrary to our expectations, therefore, the personality measure significantly moderated the observed relationships between personality and values. Additionally, more of the relationships generalized when using just the BFI, although this was not true for the NEO (though this could be a result of combining two different versions of the NEO). Relationship with values also tended to be stronger for the BFI as compared to the NEO, although we would not have predicted this a priori, and it is not clear why this should be the case. Given that the NEO and the BFI were developed using different methods, perhaps it is not surprising that the results would differ.

Statistical adjustments to control for values scale use. Abbreviated results of this moderator analysis are provided in Table 15. The z-test showed that 37 of the 50 relationships were significantly different when using different methods, so statistical adjustments act as a 
moderator. As further evidence, 28 of the 50 relationships generalized when limiting our analyses to studies using the partialling method, and 22 relationships generalized with studies using zero-order correlations. In comparing the methods, some relationships were stronger when partialling, some were stronger when using zero-order correlations, and some were about the same across the two methods. However, "stronger" does not necessarily mean better or more accurate. As the partialling method has strong theoretical support, partialling out the mean value score should provide a clearer picture of the relationships because correlations that are controlled for scale use are more accurate.

Other moderators. We also examined study population, sample size, and publication status as potential moderators. However, the three moderators were confounded with one another, as several of the larger studies were based on unpublished data from Internet studies involving the general population. None of these moderator analyses yielded clear results; in all three sets of analyses some differences emerged between the subgroups, but across the 50 correlations no subgroup was clearly superior to another. Given that the results are not particularly meaningful, in the interest of space we have not included details from these analyses (additional details regarding these moderator analyses are available on request from the first author).

\section{Discussion}

The current article presents the first meta-analysis of the relationships between personality traits and personal values, focusing on the most studied models of traits and values -Five Factor Model and the Schwartz (1992) value theory. The results show meaningful relationships, most of which were predicted $a$-priori and generally follow the sinusoidal pattern predicted by the values circle. As we expected, the strength of these relationships was a product 
of two factors: the nature of the traits (more cognitively-based traits have stronger relationships with values) and content overlap between the traits and values. The pattern of results also suggests that. although values and traits are related, the two constructs are distinct. Moderator analyses suggest that the choice of instrument (for both traits and values) sometimes impacts the results. Hypothesized links also tend to be stronger when using the PVQ to measure values as compared to the SVS, and when using the BFI to measure personality as compared to the NEO. Furthermore, relationships are more consistent with theory when response tendencies for values are statistically controlled. Additional moderator analyses do not support the idea that culture (individualism versus collectivism and tightness versus looseness cultural dimensions) affects these relationships. We next elaborate on the specific meta-analytic results and discuss their theoretical and practical implications. We then discuss some limitations and point to important future directions for research.

\section{Trait-Value Associations}

In discussing the findings of associations between traits and values, we refer both to the strengths of the links found and to the patterns of associations. With regard to the latter, as values are structured in a circle, relations with other variables should generally follow a sinusoidal pattern of gradual change in correlations as one moves around the circle.

Openness to experience. We expected this trait to have the strongest correlations with values based on the nature of openness as the most cognitively-based trait and on the overlap in content between openness and values. And indeed, of the five traits, openness to experience had some of the strongest correlations with values, showing the clearest pattern of correlations and with an almost perfect sinusoidal pattern of correlations. Individuals scoring high on openness to experience tend to value novelty (self-direction and stimulation values) and particularly novel 
ideas (self-direction) and broadmindedness (universalism values). In contrast, individuals who score low on openness to experience tend to value maintaining the world as it is and the safety it provides (tradition, conformity, and security values).

Agreeableness. Agreeableness is also strongly related to values. Individuals who score high on Agreeableness tend to value being prosocial, particularly towards people in their close environment (benevolence values) but also towards people in society in general (universalism values). They also tend to value restraining their impulses in order to fit in (conformity and tradition), possibly to facilitate getting along with others. In contrast, individuals who score low on agreeableness tend to value having resources and being dominant (power values). Similar to openness, agreeableness had a perfect sinusoidal pattern of correlations with values.

Extraversion. As we expected, extraversion correlated less strongly with values than did openness and agreeableness, but these correlations are nevertheless theoretically meaningful and generally follow a sinusoidal pattern. Individuals who score high on extraversion tend to value excitement and variety (stimulation values), as well as value enhancing their own interests through dominance, success, and having fun (power, achievement, and hedonism values).

Conscientiousness. Conscientiousness is the only trait that was not expected to have a sinusoidal pattern of correlations with values; instead, it was expected to have two peaks of correlations with values that are not adjacent to one another in the value circle (i.e., conformity and achievement). Its correlations with values generally followed the expected pattern, but it was most strongly associated with security values. Hence, this meta-analysis established that conscientious people tend to value order, adherence to rules, and the avoidance of risks. They also tend, to a lesser degree, to value fitting in (conformity) and having socially recognized 
accomplishments (achievement). In general, however, conscientiousness is less strongly associated with values compared to openness and agreeableness.

Emotional stability. As expected, emotional stability did not correlate with values. This is consistent with our premise that an affectively-based trait should not be strongly related to values, which are a cognitively-based construct. Our meta-analysis also confirms the idea expressed in a review on values and well-being (Sagiv et al., 2004) that values are not directly related to well-being.

\section{Moderators}

Culture. Our analyses were the first to examine cross-cultural differences in the relationships between traits and values. The moderator analyses showed little evidence for a cultural effect on the strength of trait-value relationships, although a larger sample size is needed before drawing firm conclusions. Still, the occasional and unsystematic cultural effects found may suggest that although people in various cultures vary on their levels of traits (e.g. Costa, Terracciano, \& McCrae, 2001) and values (e.g., Schwartz, 2011b), the relationships between traits and values remain largely consistent across cultures, at least in the current range of cultures (see John, Naumann, \& Soto, 2008 for traits; Schwartz, 2011b for values) and for the cultural variables that we considered. Additional dimensions of culture do exist and could also be considered, although we tested those that we believed were most likely to moderate these relationships. As more samples accumulate, the statistical power for answering this important question will increase.

Survey instrument. Using the PVQ to measure values often results in stronger hypothesized trait-value correlations. The PVQ scale may inflate correlations between the two constructs because its items often include trait-like components. Should researchers continue to 
use it? If an important part of a study is to measure values alone without any traces of traits, strivings, or preferences (all exist in parts of some items), and if distinguishing between values and these other characteristics of the person is important, then researchers might want to use the SVS rather than the PVQ. In all other instances, the PVQ should be adequate for use, and it has some clear advantages over the SVS (detailed in Schwartz, 2005). A newly constructed measure of values (Schwartz et al., 2012) builds on the PVQ and fewer of its items have trait-like components compared to the PVQ, but it is still not completely trait-free. Researchers may also wish to bear in mind that the content of the two instruments may sometimes be slightly different.

Similarly, the choice of personality instrument is likely to have an impact on the strength of the observed relationships between traits and values. As with the values measure, researchers should choose personality measures based on a particular study's purpose and design. We also encourage researchers to evaluate personality instruments at the item-level to determine whether the scale is accurately measuring traits or if it also includes some value-laden items. We did not expect, a priori, for the BFI to exhibit stronger relationships with values as compared to the NEO - we cannot therefore say at this point which personality instrument yields more accurate results, just that the relationships differ.

Statistical adjustments to control for values scale use. Controlling for how respondents use the rating scales in statistical analyses of correlations should result in more accurate correlations between traits and values. Such treatment of the data is in line with the understanding that values exist in a system of values; therefore the important element in linking to another variable is not so much the absolute importance given to the value but rather its importance compared to all other values—its prioritization over other values in one’s value 
system. This consideration leads to the important recommendation for researchers to control for scale use tendency in values when correlating values with other variables.

\section{Theoretical Implications}

The research literatures on personality traits and personal values share a common heritage: research on both sets of constructs originated with a reliance on the lexical hypothesis for identifying relevant content. The lexical hypothesis proposes that meaningful differences in the characteristics of individuals are encoded in language, such that a review of the dictionary for terms describing individuals will yield a comprehensive list of important characteristics (Goldberg, 1993; McCrae \& Costa, 1997; Schwartz, 1994). When Allport (1937) undertook his study of personality traits based on the lexical hypothesis, he stated that personality traits should be non-evaluative and was explicit in his efforts to remove evaluative terms that related to an individual’s “character,” or values. Until quite recently, that separation of values and traits has led the two sets of constructs to be studied mostly independently of the other.

Traits and values are independently examined as important predictors of a multitude of outcome variables in numerous contexts in various areas such as educational psychology (e.g., Knafo \& Schwartz, 2004; Poropat, 2009), organizational psychology (e.g., Berson, Oreg, \& Dvir, 2007; Lim \& Ployhart, 2004), health psychology (e.g., Bergin, 1991; Terracciano \& Costa, 2004), political psychology (e.g., Saucier, 2000; Schwartz, Caprara, \& Vecchione, 2010), environmental psychology (e.g., Grunert \& Juhl, 1995; Ramanaiah, Clump, \& Sharpe, 2000) sports psychology (e.g., Courneya \& Hellsten, 1998; Lee, Whitehead, Ntoumanis, \& Hatzigeorgiadis, 2008), occupational psychology (e.g., Sagiv, 2002; Gottfredson, Jones, Holland, 1993), social psychology (e.g., Cohrs, Moschner, Maes, \& Kielmann, 2005; Sibley \& Duckitt, 2008), and others. Only recently have researchers started to explore the combined effects of 
traits and values on various outcomes (see, e.g., Park \& Guay, 2012; Roccas et al., 2002). The present article offers the first meta-analysis of the relationships between personality traits and personal values, thereby clarifying these relationships. The results demonstrate that traits and values are related in predictable ways based both on the extent to which the trait is cognitivelybased, and on the extent to which the content of traits and values are conceptually similar.

As noted previously, researchers tend to adhere to one of three basic views of traits and values: (1) They are different ways of measuring the same thing; (2) They are unique and separate constructs at the same level of abstraction; and (3) They are both part of a hierarchy of personality, but they exist at different levels in that hierarchy. This meta-analysis clearly demonstrates that the first viewpoint is inaccurate. If traits and values were different ways of measuring the same thing, then the correlations between them should have been much stronger, demonstrating convergent validity. Yet only 18 of the 50 relationships generalized, and of those only two were strong relationships. The pattern of results therefore clearly demonstrates that although values are meaningfully linked to traits, the two constructs are distinct.

A review of the traits-values literature provides additional evidence in support of this premise; many studies have examined the differential impact of traits and values on various outcomes and constructs, providing evidence of divergent validity. For example, Roccas and colleagues (Roccas et al., 2002) found that values and traits have different patterns of correlations with religiosity (associated primarily with values but not traits) and with positive affect (associated primarily with traits but not values). Other researchers have replicated these findings with subjective well-being and life satisfaction (associated primarily with traits; Haslam, Whelan, \& Bastian, 2009; Saiz, Alvaro, \& Martinez, 2011) and with religiosity and spirituality (associated primarily with values; Saiz et al., 2011; Saroglou \& Munoz-Garcia, 2008). Parks and 
Guay (2012) found that traits and values have differential relationships with the motivational processes of goal content and goal striving. Finally, several studies have shown that values are better predictors of voting preference and voting choice than are traits (Caprara, Schwartz, Capanna, Vecchione, \& Barbaranelli, 2006; Caprara, Vecchione, \& Schwartz, 2009; DirilenGumus, Cross, \& Donmez, 2012). Clearly these are not just different ways of measuring the same thing, and including both traits and values in the same study has the potential to improve predictions of a wide array of outcomes.

As the different views on the nature of the relationships between traits and values can cause confusion in the literature, researchers who study traits and values should state their underlying assumptions and provide a consistent theoretical conceptualization connecting their work with other trait-values studies that conceptualize the link in a similar way. As an example, the HEXACO personality inventory (Lee \& Ashton, 2004) is a six-factor model that includes Honesty-Humility (not included in our study because it is not a Big 5 inventory). The HonestyHumility factor seems to largely tap values; the developers of the scale state that the common adjectives used to define the factor are "Sincere, honest, faithful/loyal, modest/unassuming, fairminded” (Ashton \& Lee, 2007, p. 154). These descriptors overlap considerably with values items; "honest” and "loyal” are both benevolence items on the Schwartz Value Survey (SVS), while the tradition scale includes the item "humble" (Schwartz, 1992, p. 7), which seems quite similar to modest and unassuming. Fair-minded would seem to fit with universalism values, which are concerned with equality and fairness in society (Schwartz, 1992). If one is of the opinion that traits and values are both aspects of personality, then the HEXACO scale may be a legitimate method for measuring personality. On the other hand, if a researcher views personality as an aggregate of traits (and not values), then this scale may not be appropriate for 
measuring personality. We therefore encourage researchers to make explicit their assumptions and definitions.

\section{Limitations}

It is important to outline the unavoidable limitations of this meta-analysis, which stemmed largely from lack of suitable studies. First, the reliability corrections, as stated previously, were based only on coefficient alpha, which does not take into account transient error. As a result, they are likely to be overestimates of the true reliability. Second, information was not available to determine whether range restriction occurred in the data, though we do not think that range restriction is a large issue in the studies examined here. Third, many of these studies were conducted in different languages, using translated scales. Given the number of studies available and the fact that not all studies indicated the language, we made no attempt to control for differences caused by the language of the instrument. Fourth, not enough studies were available in each category to enable conducting hierarchical moderator analyses, making it difficult to pinpoint which construct is causing the moderation, because moderators may be correlated (as noted above). Fifth, focusing exclusively on studies that used the Five Factor Model for traits and the Schwartz (1992) value circle for personal values led us to eliminate some studies that might be worth including when a sufficient number of such studies is available. Sixth, we examined only factor-level scores for traits, as most studies did not include facet-level scores. Finally, as noted, the moderator analyses regarding culture are likely to provide clearer results with more studies, especially studies of people from collectivist cultures. When more studies accumulate, a meta-analysis can be conducted that overcomes these limitations.

\section{Future Directions}


This meta-analysis points to the importance of three broad future directions that would enhance the integrative understanding of the person: (1) Incorporating more elements of the person in one study to enhance the understanding of the structure of enduring psychological characteristics of the person, (2) examining causal directions of different characteristics of the person to enhance the understanding of life-span development of the person, and (3) integrating research from other domains, such as neuroscience, to further inform and develop our understanding of the constructs of traits and values and how they are related.

Incorporating more elements of the person in the same study. This meta-analysis established links between two enduring characteristics of the person: traits and values. However, more elements should be included in the same study and the simultaneous relationships among multiple elements should be established empirically. In addition to traits and values, these could include goals, needs, beliefs, attitudes, and temperaments, among others. Some work has been conducted in this direction, mainly examining two types of constructs at a time (e.g., Calogero, Bardi, \& Sutton, 2009; Goodwin, Polek, \& Bardi, 2012; Roberts \& Robins, 2000), but much more work is needed as well as the inclusion of more constructs.

\section{Longitudinal directions of relations between enduring characteristics of the person.}

Although this meta-analysis provides an understanding of how traits and values relate to one another, it represents a "snapshot" of those relationships at one point in time, which may not reflect how the two influence one another across time. Theorists have suggested mechanisms for reciprocal effects of traits and values (Caprara et al., 2006; Roccas et al., 2002), and several researchers have begun to theorize and examine the possible interrelations between the two (e.g., Bilsky \& Schwartz, 1994; Olver \& Mooradian, 2003; Roccas et al., 2002; Schermer, Vernon, Maio, \& Jang, 2011). Traits are often considered more innate, hence one could argue that if one 
of these were to influence the other, it would be traits. Alternatively, one could argue that values influence traits - for example, when someone becomes a parent, the value domains of benevolence and security could become more important to them. This should change their behavior, and that behavioral change might, over time, lead to modest changes in traits. We do not, at this point, fully understand the reciprocal nature of these relationships over time, yet this is an important step for gaining an integrative view of the person and understanding how this integration comes about. We therefore encourage researchers to study this question in longitudinal research.

Integrating other research domains. The question of how traits and values are related may be more easily answered if we search broadly in the research literature for other ways to understand these constructs. Both traits and values are psychological constructs - they represent complex processes taking place within the brain. A better understanding of those neural processes may inform our understanding of how traits and values relate to one another, how much they influence one another, and how much they are influenced by genetics (nature) vs. environment (nurture). For example, the frontal lobe develops later in life than the mid-brain, not reaching full maturity until early adulthood (Sowell, Thompson, Holmes, Jernigan, \& Toga, 1999). This fact suggests that psychological processes involving the frontal lobe might be more influenced by external influences into early adulthood, while those that are processed primarily in the mid-brain may be less prone to such influence. If this is true, then stating that traits represent nature and values represent nurture is overly simplistic, because traits themselves appear to vary in the extent to which they involve the frontal lobe vs. the mid-brain. Understanding at a more fundamental level how traits and values are related to one another 
should help move the field forward in developing a more integrated conceptualization of characteristics of the individual.

\section{Conclusion}

The last decade has seen initial attempts to clarify the similarities and differences between traits and values and a preliminary exploration of the links between them. This metaanalysis establishes, for the first time, the relationships between personality traits (of the most widely-used trait model - the FFM) and personal values (of the most widely-used value model the Schwartz value theory). It also establishes for the first time a conceptual underpinning for understanding these relationships, as more cognitively-based traits demonstrate stronger relationships with values, and more emotionally-based traits exhibit weaker (or no) relationships with values. We now know that openness to experience and agreeableness are the most strongly and coherently related to values; extraversion and conscientiousness also have some meaningful relations to values; and emotional stability is generally unrelated to values. We also have established that traits and values are distinct constructs and that their relationships show little variation cross-culturally. Our moderator analyses also resulted in a recommendation for researchers to control for scale use tendency in values, and to consider carefully which survey instrument to employ as some measures (i.e., the PVQ and the BFI) tend to yield stronger traitvalue relationships than do others. The findings from this meta-analysis will enable researchers to use traits and values more effectively in their studies. Moreover, this new knowledge has prepared the ground for developing models that advance our integrative understanding of the person. 


\section{References}

(*references marked with asterisk are included in the meta-analysis)

Allik, J. (2005). Personality dimensions across cultures. Journal of Personality Disorders, 19, 212-232.

Allik, J. (2012). National differences in personality. Personality and Individual Differences, 53, 114-117.

Allport, G.W. (1937). Personality: A psychological interpretation. New York: Holt.

*Arthaud-Day, M.L., Rode, J.C., \& Turnley, W.H. (2012). Direct and Contextual Effects of Individual Values on Organizational Citizenship Behavior in Teams. Journal of Applied Psychology, 97, 792-807.

Ashton, M.C. \& Lee, K. (2007). Empirical, Theoretical, and Practical Advantages of the HEXACO Model of Personality Structure. Personality and Social Psychology Review, 11, 150-166.

Barenbaum, N. B., \& Winter, D. G. (2008). History of modern personality theory and research. In O. P. John, R. W. Robins, \& L. A. Pervin, L. A. (Eds.), Handbook of Personality: Theory and Research (3rd ed., pp. 3-26). New York. Guildford.

*Bardi, A. (2005). Values, traits, and ambiguity tolerance. Unpublished raw data.

* Bardi, A. (2008). Values and traits of First Year Psychology and Business students in Autumn 2006. Unpublished raw data.

* Bardi, A., Buchanan, K. E., Goodwin, R., Slabu, L., \& Robinson, M. P. (2014). Value stability and change during self-chosen life transitions: Self-selection vs. socialization effects. Journal of Personality and Social Psychology. 106(1), 131-147. doi: 10.1037/a0034818. 
*Bardi, A., Bull, S. \& Brown, H. L. (2008). Values, goals, and traits of undergraduate students in spring 2008. Unpublished raw data.

Bardi, A. \& Goodwin, R. (2011). The Dual Route to Value Change: Individual Processes and Cultural Moderators. Journal of Cross-Cultural Psychology, 42, 271-287.

*Bardi, A. \& Guerra, V. M. (2011). Cultural values predict coping using culture as an individual difference variable in multi-cultural samples. Journal of Cross-Cultural Psychology, 42, 908-927.

* Bardi, A., \& John, O. P. (2006). Value meanings. Unpublished raw data.

*Bardi, A., Lee, J. A., Hofmann-Towfigh, N., \& Soutar, G. (2009). The structure of intraindividual value change. Journal of Personality and Social Psychology, 97(5), 913929.

* Bardi, A., Levontin, L., \& John, O. P. (2011). Traits and values: Two separate psychological systems. In preparation.

*Bardi, A., Loader, N. S., Keen, A., \& Martin, Z. C. (2004). Values, traits, coping, and wellbeing of international students. Unpublished data.

* Barrick, M.R., Giluk, T., Shaffer, J. \& Stewart, G.S. (2006). Personality and Values data collected 2005-2006. Unpublished data.

*Barrick, M.R., Stewart, G., Zimmerman, R., Parks, L., Darnold, T., \& Dustin, S. (2005). Correlates of Individual Values, data collected 2003-2004. Unpublished data.

Bergin, A.E. (1991). Values and religious issues in psychotherapy and mental health. American Psychologist, 46, 394-403.

Berson, Y., Oreg, S., \& Dvir, T. (2007). CEO values, organizational culture and firm outcomes. Journal of Organizational Behavior, 29, 615-633. 
Bilsky, W. \& Schwartz, S.H. (1994). Values and Personality. European Journal of Personality, 8, 163-181.

*Blickle, G., Schlege, A., Fassbender, P., \& Klein, U. (2006). Some Personality Correlates of Business White-Collar Crime. Applied Psychology: An International Review, 55(2), 220233.

*Burns, M. \& Postlethwaite, B. (2007). Personality and Values data collected 2004-2005. Unpublished data.

Buss, A.H. (1989). Personality as Traits. American Psychologist, 44, 1378-1388.

Calogero, R. M., Bardi A., \& Sutton, R., (2009). A need basis for values: Associations between the need for cognitive closure and value priorities. Personality and Individual Differences, 46 (2), 154-159.

Caprara, G. V, Allesandri, G., \& Eisenberg, N. (2012). Prosociality: The Contribution of Traits, Values, and Self-Efficacy Beliefs. Journal of Personality and Social Psychology, 102, 1289-1303. DOI: 10.1037/a0025626.

*Caprara, G.V., Schwartz, S. Capanna, C., Vecchione, M, \& Barbaranelli, C. (2006). Personality and Politics: Values, Traits, and Political Choice. Political Psychology, 27, 1-28. (correlation matrix obtained on request from first author)

*Caprara, G.V. \& Vecchione, M. (2006). Le ragioni degli elettori: tratti, valori e stabilita del voto. Giornale Italiano do Psicologia, 3, 501-522.

*Caprara, G.V., Vecchione, M., \& Schwartz, S.H. (2009). Mediational role of values in linking personality traits to political orientation. Asian Journal of Social Psychology, 12, 82-94.

Cervone, D. (2005). Personality architecture: Within-person structures and processes. Annual Review of Psychology, 56, 423-452. 
Cloninger, C.R. (1994). Temperament and personality. Current Opinion in Neurobiology, 4, 266273.

Cohen, J. (1988). Statistical power analysis for the behavioral sciences $\left(2^{\text {nd }}\right.$. Ed.). Hillsdale, NJ: Lawrence Erlbaum.

*Cohrs, J. C., Kielmann, S., Maes, J., \& Moschner, B. (2005). Zur Reliabilität und Validität der Erfassung von Persönlichkeitsmerkmalen im Internet: Ergebnisse einer Längsschnittstudie [Reliability and validity of personality assessment over the Internet: Results of a longitudinal study]. In K.-H. Renner, A. Schütz \& F. Machilek (Eds.), Internet und Persönlichkeit [Internet and personality] (pp. 38-53). Göttingen, Germany: Hogrefe.

Cohrs, J.C., Moschner, B., Maes, J., \& Kielmann, S. (2005). The Motivational Bases of RightWing Authoritarianism and Social Dominance Orientation: Relations to Values and Attitudes in the Aftermath of September 11, 2001. Personality and Social Psychology Bulletin, 31, 1425-1434.

*Collins, S. \& Blum, T. (2011). Mechanisms Matter: An Examination of Motivational Linkages between Individual Differences and Leader Emergence. Unpublished manuscript.

Costa, P. T., \& McCrae, R. R. (1988). From catalog to classification: Murray’s needs and the five-factor model. Journal of Personality and Social Psychology, 55, 258-265.

Costa, P. T., JR., \& McCrae, R. R. (1992). NEO-PI-R: Professional manual. Odessa, FL: Psychological Assessment Resources.

Costa, P. Jr., Terracciano, A., McCrae, R.R. (2001). Gender differences in personality traits across cultures: Robust and surprising findings. Journal of Personality and Social Psychology, 81, 322-331. 
Courneya, K.S., \& Hellsten, L.M. (1998). Personality correlates of exercise behavior, motives, barriers, and preferences: An application of the five-factor model. Personality and Individual Differences, 24, 625-633.

De Fruyt, F., Van De Wiele, L., \& Van Heeringen, C. (2000). Cloninger's Psychobiological Model of Temperament and Character and the Five-Factor Model of Personality. Personality and Individual Differences, 29, 441-452.

*Dirilen-Gumus, Ö. (2010). The Effect of Religiosity on Political Ideology via Value Types and Personality Traits: A Comparison between Turkey and USA. Procedia - Social and Behavioral Sciences, 5, 12-17.

*Dirilen-Gumus, Ö., Cross, S.E., \& Donmez, A. (2012). Who Voted for Whom? Comparing Supporters of Obama and McCain on Value Types and Personality Traits. Journal of Applied Social Psychology, 42, 2879-2900.

*Dollinger, S.J., Leong, F.T.L., \& Ulicni, S.K. (1996). On Traits and Values: With Special Reference to Openness to Experience. Journal of Research in Personality, 30, 23-41.

Field, A.P., \& Gillett, R. (2010). How to do a meta-analysis. British Journal of Mathematical and Statistical Psychology, 63, 665-694.

Fiske, D. W. (1994). Two cheers for the Big Five! Psychological Inquiry, 5, 123-124.

Gelfand, M.J., Nishii, L.H., \& Raver, J.L. (2006). On the nature and importance of cultural tightness-looseness. Journal of Applied Psychology, 91, 1225-1244.

Gelfand, M.J., Raver, J.L., Nishii, L., Leslie, L.M., Lun, J., Lim, B.C., ...Yamaguchi, S. (2011). Differences Between Tight and Loose Cultures: A 33-Nation Study. Science, 332, 100104. 
Goldberg, L.R. (1993). The structure of phenotypic personality traits. American Psychologist, 48(1), 26-34.

*Goldberg, L.R. (2008). The Eugene-Springfield Community Sample: Information Available from the Research Participants. ORI Technical Report, 48 (1). Oregon Research Institute. (data obtained by request from author)

Goodwin, R., Polek, E., \& Bardi, A. (2012). The Temporal Reciprocity of Values and Beliefs: A Longitudinal Study within a Major Life Transition. European Journal of Personality, 26, 360-370. DOI: 10.1002/per.844.

Gottfredson, G. D., Jones, E. M., Holland, J. L. (1993). Personality and vocational interests: The relation of Holland's six interest dimensions to five robust dimensions of personality. Journal of Counselling Psychology, 40, 518-524.

Graham, J., Haidt, J. \& Nosek, B.A. (2009). Liberals and Conservatives Rely on Different Sets of Moral Foundations. Journal of Personality and Social Psychology, 96, 1029-1046.

*Graham, J., Nosek, B. A., Haidt, J., Iyer, R., Koleva, S., \& Ditto, P. H. (2011). Mapping the moral domain. Journal of Personality and Social Psychology, 101(2), 366.

Graziano, W. G., \& Eisenberg, N. (1997). Agreeableness: A dimension of personality. In R. Hogan, J. A. Johnson, \& S. R. Briggs (Eds.), Handbook of personality psychology (pp. 795-824). San Diego, CA: Academic Press.

Grunert, S. C., \& Juhl, H. J. (1995). Values, environmental attitudes, and buying organic foods. Journal of Economic Psychology, 16, 39-62.

Gunthert, K. C., Lawrence L. H., \& Armeli S. (1999). The role of neuroticism in daily stress and coping. Journal of Personality and Social Psychology, 77, 1087-1100. 
*Haslam, N., Whelan, J., \& Bastian, B. (2009). Big Five traits mediate associations between values and subjective well-being. Personality and Individual Differences, 46, 40-42.

Heine, S.J. \& Buchtel, E.E. (2009). Personality: The Universal and the Culturally Specific. Annual Review of Psychology, 60, 369-394.

Hitlin, S. \& Piliavin, J.A. (2004). Values: Reviving a Dormant Concept. Annual Review of Sociology, 30, 359-393.

Hofstede, G. (1980). Culture’s consequences: International differences in work-related values. Beverly Hills, CA: Sage.

Hofstee, W.K.B. (1994). Who should own the definition of personality? European Journal of Personality, 8, 149-162.

Hogan, J., \& Ones, D. S. (1997). Conscientiousness and integrity at work. In R. Hogan, J. A. Johnson, \& S. R. Briggs (Eds.), Handbook of personality psychology (pp. 849-872). San Diego, CA: Academic Press.

Hunter, J.E. \& Schmidt, F.L. (2004). Methods of Meta-Analysis: Correcting Error and Bias in Research Findings. Thousand Oaks, CA: Sage Publications.

John, O.P., Donahue, E.M., \& Kentle, R.L. (1991). The Big Five Inventory: Technical Report. Berkeley, CA : University of California, Berkeley.

John, O. P., \& Srivastava, S. (1999). The big five trait taxonomy: History, measurement , and theoretical perspectives. In L. A. Pervin and O. P. John (Eds.), Handbook of personality: Theory and research (2nd ed., pp. 102-138). New York: The Guilford Press.

John, O. P., Naumann, L. P., \& Soto, C. J. (2008). Paradigm shift to the integrative big five trait taxonomy: History, measurement, and conceptual issues. In O. P. John, R. W. Robins, 
and L. A. Pervin (Eds.), Handbook of personality: Theory and research (3rd ed., pp. 114158). New York: The Guilford Press.

Kandler, C. (2012). Nature and Nurture in Personality Development: The Case of Neuroticism and Extraversion. Current Directions in Psychological Science, 21, 290-296.

*Knafo, A. (2007). Unpublished data.

Knafo, A., \& Spinath, F. M. (2011). Genetic and environmental influences on girls' and boys' gender-typed and gender-neutral values. Developmental Psychology, 47(3), 726-731. doi:10.1037/a0021910

Knafo, A. \& Schwartz, S.H. (2004). Identity formation and parent-child value congruence in adolescence. British Journal of Developmental Psychology, 22, 439-458.

*Kosinski, M., \& Stillwell, D. J. (2011). myPersonality research wiki. myPersonality project. Unpublished manuscript.

* Kusdil, M. E. (2000). Value Socialisation in Cultural Context: A Study with British and Turkish Families. Unpublished PhD thesis. The University of Sussex, Brighton, UK.

Lee, K. \& Ashton, M.C. (2004). Psychometric Properties of the HEXACO Personality Inventory. Multivariate Behavioral Research, 38, 329-358.

Lee, M., Whitehead, J., Ntoumanis, N. \& Hatzigeorgiadis, A. (2008). Relationships among values, achievement orientations and attitudes in youth sport. Journal of Sport and Exercise Psychology, 30, 588-610.

Lim, B. \& Ployhart, R.E. (2004). Transformational leadership: Relations to the Five-Factor Model and Team Performance in Typical and Maximum Contexts. Journal of Applied Psychology, 89, 610-621. 
Locke, E. A. (1997). The Motivation to Work: What We Know. In Advances in Motivation and Achievement, Vol. 10, pp. 375-412. JAI Press Inc.

*Lonnqvist, J.-E. \& Versakalo (2005). Unpublished data.

*Lönnqvist, J.E. \& Walkowitz, G. (2010). Personality and Values of Students at the University of Bonn. Unpublished data.

*Luengo Kanacri, B.P., Rosa, V., \& Di Giunta, L. (2012). The Mediational Role of Values in Linking Personality Traits to Civic Engagement in Italian Youth. Journal of Prevention \& Intervention in the Community, 40, 8-21.

*Luk, C.L. \& Bond, M.H. (1993). Personality variation and values endorsement in Chinese university students. Personality and Individual Differences, 14(3), 429-437.

McAdams, D.P. (1995). What do we know when we know a person? Journal of Personality, 63, 365-396.

McAdams, D. P. (1996). Alternative futures for the study of human individuality. Journal of Research in Personality, 30, 374-378.

McAdams, D. P., \& Pals, J. L. (2006). A new Big Five: Fundamental principles for an integrative science of personality. American Psychologist, 61, 204-217.

McClelland, D.C. (1996). Does the Field of Personality Have a Future? Journal of Research in Personality, 30, 429-434.

McCrae, R. R., \& Costa, P. T., Jr. (1997). Personality trait structure as a human universal. American Psychologist, 52, 509-516.

McCrae, R.R., \& Costa, P.T.Jr. (2008). The Five-Factor Theory of Personality. In (Eds.) John, Robins, \& Pervin, Handbook of Personality: Theory and Research. Third Edition. New York: Guilford Press. 
McCrae, R.R., \& Costa, P.T.Jr. (2003). Personality in Adulthood: A Five-Factor Theory Perspective. New York: Guilford Press.

McCrae R.R. \& John, O.P. (1992). An introduction to the five-factor model and its applications. Journal of Personality, 60, 175-215.

*Olver, J.M. \& Mooradian, T.A. (2003). Personality traits and personal values: a conceptual and empirical integration. Personality and Individual Differences, 35, 109-125.

*Parks, L. (2007). Personality and Values as Predictors of Motivated Behavior. Unpublished dissertation. University of Iowa, Iowa City, IA.

*Parks, L. (2008). Personality and Values of Bank Employees. Unpublished data.

Parks, L. \& Guay, R. P. (2009). Personality, Values, and Motivation. Personality and Individual Differences, 47, 675-684.

Parks, L. \& Guay, R. P. (2012). Can Personal Values Predict Performance? Evidence in an Academic Setting. Applied Psychology: An International Review, 61, 149-173.

*Parks-Leduc, L., Pattie, M.W., Pargas, F., \& Eliason, R. (2014). Self-monitoring as an aggregate construct: Relationships with personality and values. Personality and Individual Differences, 58, 3-8.

Pelto, P.J. (1968). The differences between “tight” and “loose” societies. Society, 5, 37-40.

Peterson, R.A. (2001). On the Use of College Students in Social Science Research: Insights from a Second-Order Meta-Analysis. Journal of Consumer Research, 28, 450-461.

*Poling, T.L., Woehr, D.J., Gorman, C.A., \& Arciniega, L.M. (2006). The impact of personality and value diversity on team performance. Paper presented at the Annual Meeting for the Society for Industrial and Organizational Psychology, Dallas, TX. (individual-level data obtained by request from first author) 
Poropat, A.E. (2009). A meta-analysis of the five-factor model of personality and academic performance. Psychological Bulletin, 135, 322-338.

Pytlik Zillig,L. M., Hemenover, S.H., \& Dienstbier, R.A. (2002). What do we assess when we assess a Big 5 trait? A content analysis of the affective, behavioral, and cognitive processes represented in Big 5 personality inventories. Personality and Social Psychology Bulletin, 28, 847-858.

Ramanaiah, N.V., Clump, M., \& Sharpe, J.P. (2000). Personality Profiles of Environmentally Responsible Groups. Psychological Reports, 87, 176-178.

Roberts, B. W. \& Robins, R. W. (2000). Broad dispositions, broad aspirations: The intersection of personality traits and major life goals. Personality and Social Psychology Bulletin, 26, 1284-1296.

Roccas, S., \& Sagiv, L. (2010). Personal values and behavior : Taking the cultural context into account. Social and Personality Psychology Compass, 4, 30-41.

*Roccas, S,. Sagiv, L., \& Porat (2007). Personality traits and personal values. Unpublished raw data.

*Roccas, S., Sagiv, L., Schwartz, S.H., \& Knafo, A. (2002). The Big Five Personality Factors and Personal Values. Personality and Social Psychology Bulletin, 28(6), 789-801.

Rohan, M. J. (2000). A rose by any name? The values construct. Personality and Social Psychology Review, 4, 255-277.

Rokeach, M. (1973). The Nature of Human Values. New York, NY: The Free Press. Sagiv, L. (2002). Vocational Interests and Basic Values. Journal of Career Assessment, 10, 233-257. 
Sagiv, L., Roccas, S., \& Hazan, O. (2004). Value pathways to well-being: Healthy values, valued goal attainment, and environmental congruency. In: P. A. Lingly, \& s. Josheph (Eds.), Positive psychology in practice (pp. 68-85). John Wiley: New-Jersey.

Saiz, J., Alvaro, J.L., Martinez, I. (2011). Relacion entre rasogs de personalidad y valores personales en pacientes dependientes de la cocaine. Adicciones, 23, 125-132.

*Saraglou, V. \& Munoz-Garcia, A. (2008). Individual Differences in Religion and Spirituality: An issue of personality traits and/or values. Journal for the Scientific Study of Religion, 47, 83-101.

Saucier, G. (2000). Isms and the structure of social attitudes. Journal of Personality and Social Psychology, 78, 366-385.

Schermer, J. A., Vernon, P. A., Maio, G. R., \& Jang, K. L. (2011). A behavior genetic study of the connection between social values and personality. Twin Research and Human Genetics, 14, 233-239.

Schwartz, S. H. (1992). Universals in the Content and Structure of Values: Theoretical Advances and Empirical Tests in 20 Countries. In Mark P. Zanna (Ed.), Advances in Experimental Social Psychology, 1-65. San Diego, CA: Academic Press.

Schwartz, S. H. (1994). Are There Universal Aspects in the Structure and Contents of Human Values? Journal of Social Issues, 50(4), 19-45.

Schwartz, S. H. (1996). Value priorities and behavior: Applying a theory of integrated value systems. In C. Seligman, J. M. Olson, \& M. P. Zanna (Eds.), The Ontario Symposium: Vol. 8. The psychology of values (pp. 1-24). Hillsdale, NJ: Erlbaum. 
Schwartz, S. H. (2004). Mapping and interpreting cultural differences around the world. In H. Vinken, J. Soeters, \& P Ester (Eds.), Comparing cultures, Dimensions of culture in a comparative perspective (pp.43-73). Leiden, The Netherlands: Brill.

Schwartz, S. H. (2005). Robustness and fruitfulness of a theory of universals in individual human values. In A. Tamayo \& J. B. Porto (Eds.), Valores e comportamento nas organizaç Atoes [Values and behavior in organizations] (pp. 56-95). Petrópolis, Brazil: Vozes.

Schwartz, S. H. (2011a). Studying values: Personal adventure, future directions. Journal of Cross-Cultural Psychology, 42, 307-319.

Schwartz, S. H. (2011b). Values: Individual and cultural. In F. J. R. van de Vijver (Eds.), A. Chasiotis, \& S. M. Breugelmans, Fundamental questions in cross-cultural psychology (pp. 463-493). Cambridge: Cambridge University Press.

Schwartz, S. H. \& Bardi, A. (2001). Value Hierarchies across Cultures: Taking a Similarities Perspective. Journal of Cross-Cultural Psychology, 32, 268-290.

Schwartz, S. H. \& Bilsky, W. (1987). Toward a psychological structure of human values. Journal of Personality and Social Psychology, 53, 550-562.

Schwartz, S.H., Caprara, G.V., \& Vecchione, M. (2010). Basic Personal Values, Core Political Values, and Voting: A Longitudinal Analysis. Political Psychology, 31, 421-452.

Schwartz, S. H., Cieciuch, J., Vecchione, M., Davidov, E., Fischer, R., Beierlein, C., Ramos, A., Verkasalo, M., Lönnqvist, J.-E., Demirutku, K., Dirilen-Gumus, O., \& Konty, M. (2012). Refining the theory of basic individual values. Journal of Personality and Social Psychology,103, 663-688. doi: 10.1037/a0029393. 
Schwartz, S. H., Melech, G., Lehmann, A., Burgess, S., Harris, M., \& Owens, V. (2001).

Extending the cross-cultural validity of the theory of basic human values with a different method of measurement._Journal of Cross Cultural Psychology, 32, 519-542.

Schwartz, S. H., Sagiv, L., \& Boehnke, K. (2000). Worries and values. Journal of Personality, 68(2), 309-346.

Sheldon, K.M. (2004). Optimal Human Being: An Integrated Multi-level Perspective. Mahwah, New Jersey: Lawrence Erlbaum Associates, Inc.

Sheldon, K.M. \& Elliot, A.J. (1999). Goal striving, need satisfaction, and longitudinal wellbeing: The self-concordance model. Journal of Personality and Social Psychology, 76, 482-497.

Shoda, Y., \& Mischel, W. (2006). Applying meta-theory to achieve generalizability and precision in personality science. Applied Psychology: An International Review, 55, 439452.

Sibley, C.G \& Duckitt, J. (2008). Personality and Prejudice: A Meta-Analysis and Theoretical Review. Personality and Social Psychology Review, 12, 248-279.

Smith, P. B., \& Bond, M. H. (1998). Social psychology across cultures ( $2^{\text {nd }}$ ed.). London: Prentice Hall Europe.

*Stankov, L. (2007). The Structure Among Measures of Personality, Social Attitudes, Values, and Social Norms. Journal of Individual Differences, 28, 240-251. (correlations obtained on request from author)

*Steca, P., Monzani, D., \& Greco, A. (2011). Valori, Motivi e Tratti di Personalità. Differenze tra Persone e Tipi di Persone ("Values, motives, and traits. Individual differences and 
Types”). In G.V. Caprara, E. Scabini, P. Steca \& S.H. Schwartz (Eds.), I valori nell’Italia contemporanea ("Values in contemporary Italy") (pp. 69-93). Milano: Franco Angeli.

Steel, P.D. and Kammeyer-Mueller, J.D. (2002). Comparing Meta-Analytic Moderator Estimation Techniques Under Realistic Conditions. Journal of Applied Psychology, 87, 96-111.

Sowell, E.R., Thompson, P.M., Holmes, C.J., Jernigan, T.L., \& Toga, A.W. (1999). In vivo evidence for post-adolescent brain maturation in frontal and striatal regions. Nature Neuroscience, 2, 859-861.

Suh, E., Diener, E., Oishi, S., \& Triandis, H. C. (1998). The shifting basis of life satisfaction judgments across cultures: Emotions versus norms. Journal of Personality and Social Psychology, 74, 482-493.

*Sverdik, N., \& Sagiv, L. (2007). Unpublished data.

Taras, V., Kirkman, B.L., \& Steel, P. (2010). Examining the impact of Culture’s Consequences: A three-decade, multilevel, meta-analytic review of Hofstede’s cultural value dimensions. Journal of Applied Psychology, 95, 405-439.

Terracciano, A. \& Costa, P.T. Jr. (2004). Smoking and the Five-Factor Model of personality. Addiction, 99, 472-481.

*Trapnell, P. (2007). Unpublished data, University of Winnipeg.

* Uziel, L., Sagiv, L. \& Roccas, S. (2007). Personality traits and personal values. Unpublished data.

*Vecchione, M., Alessandri, G., Barbaranelli, C., \& Caprara, G. (2011). Higher-order factors of the big five and basic values: Empirical and theoretical relations. British Journal of Psychology, 102, 478-498. 
*Vecchione, M., Caprara, G., Schoen, H., Castro, J.L.G., \& Schwartz, S.H. (2012). The role of personal values and basic traits in perceptions of the consequences of immigration: A three-nation study. British Journal of Psychology, 103, 359-377.

*Vecchione, M. \& Mebane, M. (2007) Unpublished data.

von Collani, G. \& Grumm, M. (2009). On the Dimensional Structure of Personality, Ideological Beliefs, Social Attitudes, and Personal Values. Journal of Individual Differences, 30, 107-119.

*Wijnen, K., Vermeir, I., \& Van Kenhove, P. (2007). The relationships between traits, personal values, topic involvement, and topic sensitivity in a mail survey context. Personality and Individual Differences,42, 61-73. (personality and values correlations obtained by request from first author)

*Wilson, R.E., Gosling, S.D., \& Graham, L.T. (2012). A Review of Facebook Research in the Social Sciences. Perspectives on Psychological Science, 7, 203. DOI:

$10.1177 / 1745691612442904$

Winter, D.G., John, O.P., Stewart, A.J., Klohnen, E.C., \& Duncan, L.E. (1998). Traits and motives: Toward an integration of two traditions in personality research. Psychological Review, 105, 230-251.

*Wolfradt, U. \& Dalbert, C. (2003). Personality, values, and belief in a just world. Personality and Individual Differences, 35, 1911-1918.

*Xu, X. (2005). OCB through Cultural Lenses: Exploring the Relations among Personality, OCB, and Cultural Values. Paper presented at the Academy of Management Annual Conference. Honolulu, HI. 
*Yik, M.S.M. \& Tang, C.S. (1996). Linking Personality and Values: The importance of a culturally relevant personality scale. Personality and Individual Differences, 21(5), 767774. 
Table 1

Five Factor Model of Personality

\section{Construct}

Openness to Experience

Agreeableness

Extraversion

Conscientiousness

Emotional Stability
Description: The extent to which individuals tend to be...

...curious, intellectual, imaginative, creative, innovative, and

flexible (vs. closed-minded, shallow, and simple)

...helpful, good-natured, cooperative, sympathetic, trusting, and forgiving (vs. rude, selfish, hostile, uncooperative, and unkind)

... sociable, talkative, optimistic, ambitious, assertive, reward-seeking, outgoing, and energetic (vs. introverted, shy, reserved, quiet, and unadventurous)

...organized, responsible, dependable, neat, efficient, and achievement-oriented (vs. disorganized, lazy, irresponsible, careless, and sloppy)

... calm, self-confident, stable, resilient, and well-adjusted (vs. neurotic, nervous, insecure, fearful, and anxious) 
Table 2

Schwartz Value Taxonomy

\begin{tabular}{ll}
\hline Construct: & $\begin{array}{l}\text { Description/Items: } \\
\text { Individuals who value this believe in the importance of... }\end{array}$ \\
\hline Power & $\begin{array}{l}\text {.. being in charge of people and resources and having } \\
\text { money (social power, wealth, authority ) }\end{array}$ \\
Achievement & $\ldots$ socially-recognized successes (ambition, competence) \\
Hedonism & $\ldots$...ensual pleasure (fun, enjoying life) \\
Stimulation & $\ldots$ having stimulating experiences (daring, exciting life) \\
Self-direction & $\ldots$ independence of thought and action (creativity, freedom, \\
Universalism & $\begin{array}{l}\text { independent, curious) } \\
\text { Benevolence }\end{array}$ \\
social justice, protecting the environment) \\
Conformity
\end{tabular}


Table 3

Studies included in the meta-analysis; possible moderators

\begin{tabular}{|c|c|c|c|c|c|c|c|c|}
\hline & Study & $\mathbf{N}$ & $\begin{array}{l}\text { Personality } \\
\text { Measure }\end{array}$ & $\begin{array}{l}\text { Values } \\
\text { Measure }\end{array}$ & Country & $\begin{array}{l}\text { Sample } \\
\text { population }\end{array}$ & $\begin{array}{l}\text { Method of } \\
\text { analysis* }\end{array}$ & $\begin{array}{l}\text { Publication } \\
\text { Status }\end{array}$ \\
\hline 1. & $\begin{array}{l}\text { Arthaud-Day, Rode, \& Turnley, } \\
2012\end{array}$ & 582 & IPIP & SVS & USA & Students & Partialled & $\begin{array}{l}\text { Published } \\
\text { article }\end{array}$ \\
\hline 2. & Bardi, 2005 & 103 & BFI & SVS & UK & Students & Partialled & Unpublished \\
\hline 3. & Bardi, 2008 & 677 & TIPI & SVS & UK & Students & Partialled & Unpublished \\
\hline 4. & $\begin{array}{l}\text { Bardi, Buchanan, Goodwin, } \\
\text { Slabu, \& Robinson, } 2014\end{array}$ & 136 & $\mathrm{BFI}$ & SVS & UK & Police trainees & Partialled & $\begin{array}{l}\text { Published } \\
\text { article }\end{array}$ \\
\hline 5. & Bardi, Bull, \& Brown, 2008 & 65 & $\mathrm{BFI}$ & SVS & UK & Students & Partialled & Unpublished \\
\hline 6. & Bardi \& Guerra, 2011 & 163 & BFI & SVS & World & Students & Partialled & $\begin{array}{l}\text { Published } \\
\text { article }\end{array}$ \\
\hline 7. & Bardi \& John, 2006 & 110 & $\mathrm{BFI}$ & SVS & UK & Students & Partialled & Unpublished \\
\hline 8. & $\begin{array}{l}\text { Bardi, Lee, Hofmann-Towfigh, } \\
\text { \& Soutar, } 2009 \text { (a) }\end{array}$ & 128 & BFI & SVS & UK & Students & Partialled & $\begin{array}{l}\text { Published } \\
\text { article }\end{array}$ \\
\hline 9. & $\begin{array}{l}\text { Bardi, Lee, Hofmann-Towfigh, } \\
\text { \& Soutar, } 2009 \text { (b) }\end{array}$ & 196 & BFI & SVS & UK & Students & Partialled & $\begin{array}{l}\text { Published } \\
\text { article }\end{array}$ \\
\hline 10. & Bardi, Levontin \& John, 2011 & 586 & $\begin{array}{l}\text { BFI, NEO, \& } \\
\text { Saucier's mini- } \\
\text { markers }\end{array}$ & $\begin{array}{l}\text { SVS \& } \\
\text { PVQ }\end{array}$ & USA & Students & Partialled & Unpublished \\
\hline 11. & $\begin{array}{l}\text { Bardi, Loader, Keen, \& Martin, } \\
2004\end{array}$ & 232 & BFI & SVS & World & Students & Partialled & Unpublished \\
\hline 12. & $\begin{array}{l}\text { Barrick, Giluk, Shaffer, \& } \\
\text { Stewart, } 2006\end{array}$ & 126 & PCI & PCVS & USA & Students & Correlations & Unpublished \\
\hline 13. & $\begin{array}{l}\text { Barrick, Stewart, Zimmerman, } \\
\text { Parks, Darnold, \& Dustin, } 2005\end{array}$ & 166 & PCI & SVS & USA & Students & Correlations & Unpublished \\
\hline 14. & $\begin{array}{l}\text { Blickle, Schlege, Fassbender, \& } \\
\text { Klein, } 2006\end{array}$ & 226 & $\mathrm{NEO}$ & SVS & Germany & $\begin{array}{l}76 \text { white-collar } \\
\text { criminals; } 150 \\
\text { managers }\end{array}$ & Correlations & $\begin{array}{l}\text { Published } \\
\text { article }\end{array}$ \\
\hline 15. & Burns \& Postlethwaite, 2007 & 159 & PCI & SVS & USA & Students & Correlations & Unpublished \\
\hline
\end{tabular}




\begin{tabular}{|c|c|c|c|c|c|c|c|c|}
\hline & Study & $\mathbf{N}$ & $\begin{array}{l}\text { Personality } \\
\text { Measure }\end{array}$ & $\begin{array}{l}\text { Values } \\
\text { Measure }\end{array}$ & Country & $\begin{array}{l}\text { Sample } \\
\text { population }\end{array}$ & $\begin{array}{l}\text { Method of } \\
\text { analysis* }\end{array}$ & $\begin{array}{l}\text { Publication } \\
\text { Status }\end{array}$ \\
\hline 16. & $\begin{array}{l}\text { Caprara, Schwartz, Capanna, } \\
\text { Vecchione, \& Barbaranelli, } \\
2006\end{array}$ & 4349 & BFQ & PVQ & Italy & $\begin{array}{l}\text { General } \\
\text { population }\end{array}$ & Unknown & $\begin{array}{l}\text { Published } \\
\text { article }\end{array}$ \\
\hline 17. & Caprara \& Vecchione, 2006 & 944 & BFQ & PVQ & Italy & $\begin{array}{l}\text { General } \\
\text { population }\end{array}$ & Correlations & $\begin{array}{l}\text { Published } \\
\text { article }\end{array}$ \\
\hline 18. & $\begin{array}{l}\text { Caprara, Vecchione, \& } \\
\text { Schwartz, } 2009\end{array}$ & 576 & BFQ & PVQ & Italy & Students & Unknown & $\begin{array}{l}\text { Published } \\
\text { article }\end{array}$ \\
\hline 19. & $\begin{array}{l}\text { Cohrs, Kielmann, Maes, \& } \\
\text { Moschner, } 2005\end{array}$ & 512 & NEO & SVS & World & $\begin{array}{l}\text { General } \\
\text { population }\end{array}$ & Partialled & $\begin{array}{l}\text { Published book } \\
\text { chapter }\end{array}$ \\
\hline 20. & Collins \& Blum, 2011 & 199 & IPIP & SVS & USA & Students & Centered & Unpublished \\
\hline 21. & Dirilen-Gumus, 2010 (a) & 386 & BFI & PVQ & USA & Students & Unknown & $\begin{array}{l}\text { Published } \\
\text { article }\end{array}$ \\
\hline 22. & Dirilen-Gumus, 2010 (b) & 382 & BFI & PVQ & Turkey & Students & Unknown & $\begin{array}{l}\text { Published } \\
\text { article }\end{array}$ \\
\hline 23. & $\begin{array}{l}\text { Dirilen-Gumus, Cross, \& } \\
\text { Donmez, } 2012\end{array}$ & 278 & BFI & PVQ & USA & $\begin{array}{l}\text { General } \\
\text { population \& } \\
\text { Students }\end{array}$ & Correlations & $\begin{array}{l}\text { Published } \\
\text { article }\end{array}$ \\
\hline 24. & $\begin{array}{l}\text { Dollinger, Leong, \& Ulicni, } \\
1996 \text { (a) }\end{array}$ & 275 & NEO & RVS & USA & Students & Standardized & $\begin{array}{l}\text { Published } \\
\text { article }\end{array}$ \\
\hline 25. & $\begin{array}{l}\text { Dollinger, Leong, \& Ulicni, } \\
1996 \text { (b) }\end{array}$ & 198 & NEO & RVS & USA & Students & Standardized & $\begin{array}{l}\text { Published } \\
\text { article }\end{array}$ \\
\hline 26. & Goldberg, 2008 & 698 & IPIP & SVS & USA & $\begin{array}{l}\text { General } \\
\text { population }\end{array}$ & Partialled & Unpublished \\
\hline 27. & $\begin{array}{l}\text { Haslam, Whelan, \& Bastian, } \\
2009\end{array}$ & 180 & IPIP & SVS & Australia & Students & Partialled & $\begin{array}{l}\text { Published } \\
\text { article }\end{array}$ \\
\hline 28. & Knafo, 2007 & 278 & $\begin{array}{l}\text { Saucier's mini- } \\
\text { markers }\end{array}$ & SVS & Israel & Students & Correlations & Unpublished \\
\hline 29. & Kusdil, 2000 (a) & 147 & NEO & SVS & UK & $\begin{array}{l}\text { General } \\
\text { population }\end{array}$ & Partialled & Dissertation \\
\hline 30. & Kusdil, 2000 (b) & 329 & NEO & SVS & Turkey & $\begin{array}{l}\text { General } \\
\text { population }\end{array}$ & Partialled & Dissertation \\
\hline
\end{tabular}




\begin{tabular}{|c|c|c|c|c|c|c|c|c|}
\hline & Study & $\mathbf{N}$ & $\begin{array}{l}\text { Personality } \\
\text { Measure }\end{array}$ & $\begin{array}{l}\text { Values } \\
\text { Measure }\end{array}$ & Country & $\begin{array}{l}\text { Sample } \\
\text { population }\end{array}$ & $\begin{array}{l}\text { Method of } \\
\text { analysis* }\end{array}$ & $\begin{array}{l}\text { Publication } \\
\text { Status }\end{array}$ \\
\hline 31. & Lonnqvist \& Versakalo, 2005 & 498 & NEO & SVS & Finland & $\begin{array}{l}\text { Military } \\
\text { (Reserve } \\
\text { Officer School) }\end{array}$ & Correlations & Unpublished \\
\hline 32. & Lonnqvist \& Walkowitz, 2010 & 120 & Short Five & PVQ & Germany & Students & Correlations & Unpublished \\
\hline 33. & $\begin{array}{l}\text { Luengo Kanacri, Rosa, \& Di } \\
\text { Giunta, } 2012\end{array}$ & 563 & $\mathrm{BFQ}$ & PVQ & Italy & $\begin{array}{l}\text { General } \\
\text { population \& } \\
\text { Students }\end{array}$ & Correlations & $\begin{array}{l}\text { Published } \\
\text { article }\end{array}$ \\
\hline 34. & Luk \& Bond, 1993 & 114 & NEO & SVS & China & Students & Partialled & $\begin{array}{l}\text { Published } \\
\text { article }\end{array}$ \\
\hline 35. & $\begin{array}{l}\text { MyPersonality - } 100 \text { items } \\
\text { (Kosinski \& Stillwell, 2011) }\end{array}$ & 2986 & NEO & SVS & World & Internet & Partialled & Unpublished \\
\hline 36. & $\begin{array}{l}\text { MyPersonality - } 20 \text { items } \\
\text { (Kosinski \& Stillwell, 2011) }\end{array}$ & 1487 & NEO & SVS & World & Internet & Partialled & Unpublished \\
\hline 37. & $\begin{array}{l}\text { MyType (Wilson, Gosling \& } \\
\text { Graham, 2012) }\end{array}$ & 15805 & BFI & PVQ & World & Internet & Correlations & Unpublished \\
\hline 38. & Olver \& Mooradian, 2003 & 255 & $\begin{array}{l}\text { NEO \& Saucier’s } \\
\text { mini-markers }\end{array}$ & SVS & USA & Students & Correlations & $\begin{array}{l}\text { Published } \\
\text { article }\end{array}$ \\
\hline 39. & Parks, 2007 & 367 & IPIP & RSVS & USA & Students & Correlations & Dissertation \\
\hline 40. & Parks, 2008 & 74 & IPIP & RSVS & USA & Employees & Correlations & Unpublished \\
\hline 41. & $\begin{array}{l}\text { Parks-Leduc, Pattie, Pargas, \& } \\
\text { Eliason, } 2014\end{array}$ & 420 & IPIP & RSVS & USA & Students & Correlations & Unpublished \\
\hline 42. & $\begin{array}{l}\text { Poling, Woehr, Gorman, \& } \\
\text { Arciniega, } 2006\end{array}$ & 266 & $\begin{array}{l}\text { Saucier's } \\
\text { Unipolar } \\
\text { Markers }\end{array}$ & PVQ & USA & Students & Correlations & $\begin{array}{l}\text { Conference } \\
\text { paper }\end{array}$ \\
\hline 43. & Roccas, Sagiv, \& Porat, 2007 & 217 & $\begin{array}{l}\text { Saucier's mini- } \\
\text { markers }\end{array}$ & PVQ & Israel & Students & Partialled & Unpublished \\
\hline 44. & $\begin{array}{l}\text { Roccas, Sagiv, Schwartz, \& } \\
\text { Knafo, } 2002\end{array}$ & 246 & NEO & SVS & Israel & Students & Partialled & $\begin{array}{l}\text { Published } \\
\text { article }\end{array}$ \\
\hline 45. & $\begin{array}{l}\text { Saroglou \& Munoz-Garcia, } \\
2008\end{array}$ & 256 & NEO & SVS & Spain & Students & Partialled & $\begin{array}{l}\text { Published } \\
\text { article }\end{array}$ \\
\hline 46. & Stankov, 2007 & 1255 & IPIP & SVS & USA & Students & Unknown & $\begin{array}{l}\text { Published } \\
\text { article }\end{array}$ \\
\hline
\end{tabular}




\begin{tabular}{|c|c|c|c|c|c|c|c|c|}
\hline & Study & $\mathbf{N}$ & $\begin{array}{l}\text { Personality } \\
\text { Measure }\end{array}$ & $\begin{array}{l}\text { Values } \\
\text { Measure }\end{array}$ & Country & $\begin{array}{l}\text { Sample } \\
\text { population }\end{array}$ & $\begin{array}{l}\text { Method of } \\
\text { analysis* }\end{array}$ & $\begin{array}{l}\text { Publication } \\
\text { Status }\end{array}$ \\
\hline$\overline{47 .}$ & Steca, Monzani, \& Greco, 2011 & 4285 & BFQ & PVQ & Italy & $\begin{array}{l}\text { General } \\
\text { population }\end{array}$ & Unknown & Unpublished \\
\hline 48. & Sverdlik \& Sagiv, 2007 & 272 & $\begin{array}{l}\text { Saucier’s mini- } \\
\text { markers }\end{array}$ & SVS & Israel & Students & Partialled & Unpublished \\
\hline 49. & Trapnell, 2007 & 249 & BFI & PVQ & Canada & Students & Partialled & Unpublished \\
\hline 50. & Uziel, Sagiv, \& Roccas, 2007 & 170 & $\begin{array}{l}\text { Saucier's mini- } \\
\text { markers }\end{array}$ & SVS & Israel & Students & Unknown & Unpublished \\
\hline 51. & $\begin{array}{l}\text { Vecchione, Alessandri, } \\
\text { Barbaranelli, \& Caprara, } 2011\end{array}$ & 1675 & Unique to study & PVQ & Italy & $\begin{array}{l}\text { General } \\
\text { population }\end{array}$ & Correlations & $\begin{array}{l}\text { Published } \\
\text { article }\end{array}$ \\
\hline 52. & $\begin{array}{l}\text { Vecchione, Caprara, Schoen, } \\
\text { Castro, \& Schwartz, } 2012 \text { (a) }\end{array}$ & 981 & BFQ & PVQ & Italy & $\begin{array}{l}\text { General } \\
\text { population }\end{array}$ & Partialled & $\begin{array}{l}\text { Published } \\
\text { article }\end{array}$ \\
\hline 53. & $\begin{array}{l}\text { Vecchione, Caprara, Schoen, } \\
\text { Castro, \& Schwartz, } 2012 \text { (b) }\end{array}$ & 352 & BFQ & PVQ & Spain & $\begin{array}{l}\text { General } \\
\text { population }\end{array}$ & Partialled & $\begin{array}{l}\text { Published } \\
\text { article }\end{array}$ \\
\hline 54. & $\begin{array}{l}\text { Vecchione, Caprara, Schoen, } \\
\text { Castro, \& Schwartz, } 2012 \text { (c) }\end{array}$ & 190 & NEO & PVQ & Germany & $\begin{array}{l}\text { General } \\
\text { population }\end{array}$ & Partialled & $\begin{array}{l}\text { Published } \\
\text { article }\end{array}$ \\
\hline 55. & Vecchione \& Mebane, 2007 & 1089 & $\mathrm{BFQ}$ & PVQ & Italy & $\begin{array}{l}\text { General } \\
\text { population }\end{array}$ & Correlations & $\begin{array}{l}\text { Published } \\
\text { article }\end{array}$ \\
\hline 56. & $\begin{array}{l}\text { Wijnen, Vermier, \& Van } \\
\text { Kenhove, } 2007\end{array}$ & 311 & $\begin{array}{l}\text { Mervielde’s Big } \\
\text { Five Scale }\end{array}$ & SVS & Belgium & Students & Correlations & $\begin{array}{l}\text { Published } \\
\text { article }\end{array}$ \\
\hline 57. & Wolfradt \& Dalbert, 2003 & 212 & NEO & SVS & Austria & $\begin{array}{l}104 \text { students; } \\
107 \text { general } \\
\text { population }\end{array}$ & Correlations & $\begin{array}{l}\text { Published } \\
\text { article }\end{array}$ \\
\hline 58. & Xu, 2005 & 126 & IPIP & SVS & USA \& China & Employees & Correlations & $\begin{array}{l}\text { Conference } \\
\text { paper }\end{array}$ \\
\hline 59. & Yik \& Tang, 1996 & 216 & Unique to study & SVS & Hong Kong & Students & Correlations & $\begin{array}{l}\text { Published } \\
\text { article }\end{array}$ \\
\hline 60. & $\begin{array}{l}\text { YourMorals.org (Graham et al., } \\
\text { 2011) }\end{array}$ & 7543 & BFI & SVS & World & Internet & Correlations & Unpublished \\
\hline
\end{tabular}


Table 4

Average Reliabilities (Coefficient Alpha)

\begin{tabular}{lc}
\hline Construct & Reliability \\
\hline Openness to Experience & .76 \\
Agreeableness & .73 \\
Extraversion & .78 \\
Conscientiousness & .80 \\
Emotional Stability & .81 \\
Power & .72 \\
Achievement & .76 \\
Hedonism & .72 \\
Stimulation & .73 \\
Self Direction & .67 \\
Universalism & .78 \\
Benevolence & .72 \\
Conformity & .68 \\
Tradition & .63 \\
Security & .65 \\
\hline
\end{tabular}


Table 5

Meta-analytic Results for Openness to Experience and Values

\begin{tabular}{|c|c|c|c|c|c|c|c|c|c|c|}
\hline 10-factor Value Domains & $\mathbf{k}$ & $\mathbf{N}$ & Mean $\mathbf{r}$ & $\rho$ & $\mathbf{S D}_{\rho}$ & $\mathrm{CV}_{\mathrm{LL}}$ & $\mathrm{CV}_{\mathrm{UL}}$ & $\mathbf{C I}_{\mathrm{LL}}$ & $\mathbf{C I}_{\mathrm{UL}}$ & $\%$ Var \\
\hline Power & 52 & 54274 & -.04 & -.06 & .11 & -.20 & .08 & -.27 & .15 & 13 \\
\hline Achievement & 54 & 54747 & .08 & .11 & .12 & -.04 & .26 & -.12 & .34 & 11 \\
\hline Hedonism & 53 & 54165 & .07 & .09 & .12 & -.06 & .24 & -.14 & .32 & 11 \\
\hline Stimulation & 51 & 53692 & .27 & .36 & .13 & .20 & .52 & .11 & .61 & 8 \\
\hline Self-Direction & 55 & 54959 & .37 & .52 & .11 & .38 & .66 & .31 & .74 & 11 \\
\hline Universalism & 53 & 54165 & .25 & .33 & .10 & .20 & .46 & .12 & .53 & 12 \\
\hline Benevolence & 54 & 54747 & .10 & .13 & .11 & -.01 & .27 & -.08 & .34 & 13 \\
\hline Conformity & 55 & 54959 & -.20 & -.27 & .16 & -.48 & -.07 & -.59 & .04 & 6 \\
\hline Tradition & 51 & 53692 & -.21 & -.31 & .15 & -.50 & -.12 & -.60 & -.02 & 8 \\
\hline Security & 54 & 54377 & -.17 & -.24 & .17 & -.45 & -.02 & -.56 & .09 & 6 \\
\hline
\end{tabular}

Note: $\mathrm{k}$ = number of studies; $\mathrm{N}=$ total number of individuals across all studies; Mean $\mathrm{r}=$ the average of the uncorrected correlations; $\rho=$ the estimated true score correlation; $\mathrm{SD}_{\mathrm{r}}=$ standard deviation of mean $\mathrm{r} ; \mathrm{SD}_{\rho}=$ the standard deviation of the corrected correlations; $\mathrm{CV}_{\mathrm{LL}}$ and $\mathrm{CV} \mathrm{UL}_{\mathrm{UL}}=$ lower and upper bounds, respectively, of the $80 \%$ credibility interval; $90 \% \mathrm{CV}=$ the $90 \%$ Credibility Value - this is the upper limit of the $80 \%$ credibility interval; $\mathrm{CI}_{\mathrm{LL}}$ and $\mathrm{CI}_{\mathrm{UL}}=$ lower and upper bounds, respectively, of the 95\% confidence interval around the corrected mean correlation; $\% \operatorname{Var}=$ the percentage of variance that was accounted for by statistical artifacts (sampling error and unreliability of measures). Bolded Mean $r$ values have a $95 \%$ confidence interval that does not include 0 . Bolded $\rho$ values have an $80 \%$ credibility interval that does not include 0 . 
Table 6

Meta-analytic Results for Agreeableness and Values

\begin{tabular}{|c|c|c|c|c|c|c|c|c|c|c|}
\hline 10-factor Value Domains & $\mathbf{k}$ & $\mathbf{N}$ & Mean $\mathbf{r}$ & $\rho$ & SD $_{\rho}$ & $\mathrm{CV}_{\mathrm{LL}}$ & $\mathrm{CV}_{\mathrm{UL}}$ & $\mathbf{C I}_{\mathrm{LL}}$ & CIUL $_{\text {UL }}$ & $\%$ Var \\
\hline Power & 54 & 54599 & -.31 & -.42 & .21 & -.70 & -.15 & -.84 & .00 & 3 \\
\hline Achievement & 55 & 54946 & -.18 & -.24 & .24 & -.54 & .07 & -.71 & .23 & 3 \\
\hline Hedonism & 53 & 54165 & -.08 & -.11 & .11 & -.24 & .03 & -.32 & .10 & 13 \\
\hline Stimulation & 51 & 53692 & -.04 & -.05 & .11 & -.19 & .09 & -.26 & .17 & 13 \\
\hline Self-Direction & 55 & 54959 & -.04 & -.07 & .19 & -.31 & .18 & -.45 & .32 & 5 \\
\hline Universalism & 54 & 54364 & .29 & .39 & .12 & .23 & .54 & .15 & .62 & 9 \\
\hline Benevolence & 56 & 55072 & .45 & .61 & .17 & .39 & .82 & .28 & .94 & 4 \\
\hline Conformity & 55 & 54959 & .18 & .26 & .11 & .12 & .39 & .05 & .47 & 14 \\
\hline Tradition & 51 & 53692 & .15 & .22 & .12 & .08 & .37 & .00 & .45 & 13 \\
\hline Security & 54 & 54377 & .00 & .00 & .17 & -.22 & .22 & -.34 & .34 & 6 \\
\hline
\end{tabular}

Note: $\mathrm{k}$ = number of studies; $\mathrm{N}=$ total number of individuals across all studies; Mean $\mathrm{r}=$ the average of the uncorrected correlations; $\rho=$ the estimated true score correlation; $\mathrm{SD}_{\mathrm{r}}=$ standard deviation of mean $\mathrm{r} ; \mathrm{SD}_{\rho}=$ the standard deviation of the corrected correlations; $\mathrm{CV}_{\mathrm{LL}}$ and $\mathrm{CV} \mathrm{VL}_{\mathrm{UL}}=$ lower and upper bounds, respectively, of the $80 \%$ credibility interval; $90 \% \mathrm{CV}=$ the $90 \%$ Credibility Value - this is the upper limit of the $80 \%$ credibility interval; $\mathrm{CI}_{\mathrm{LL}}$ and $\mathrm{CI}_{\mathrm{UL}}=$ lower and upper bounds, respectively, of the 95\% confidence interval around the corrected mean correlation; $\% \operatorname{Var}=$ the percentage of variance that was accounted for by statistical artifacts (sampling error and unreliability of measures). Bolded Mean $r$ values have a $95 \%$ confidence interval that does not include 0 . Bolded $\rho$ values have an $80 \%$ credibility interval that does not include 0 . 
Table 7

Meta-analytic Results for Extraversion and Values

\begin{tabular}{|c|c|c|c|c|c|c|c|c|c|c|}
\hline 10-factor Value Domains & $\mathbf{k}$ & $\mathbf{N}$ & Mean $\mathbf{r}$ & $\rho$ & SD $_{\rho}$ & $\mathbf{C V}_{\text {LL }}$ & $\mathrm{CV}_{\mathrm{UL}}$ & $\mathbf{C I}_{\mathrm{LL}}$ & $\mathbf{C I}_{\mathrm{UL}}$ & $\%$ Var \\
\hline Power & 54 & 54599 & .23 & .31 & .17 & .09 & .52 & -.02 & .63 & 5 \\
\hline Achievement & 55 & 54946 & .23 & .31 & .16 & .10 & .52 & -.01 & .63 & 6 \\
\hline Hedonism & 53 & 54165 & .16 & .20 & .09 & .09 & .32 & .02 & .39 & 15 \\
\hline Stimulation & 51 & 53692 & .28 & .36 & .07 & .27 & .45 & .22 & .50 & 22 \\
\hline Self-Direction & 55 & 54959 & .12 & .17 & .17 & -.05 & .38 & -.16 & .49 & 6 \\
\hline Universalism & 54 & 54364 & -.05 & -.05 & .15 & -.25 & .14 & -.35 & .24 & 7 \\
\hline Benevolence & 56 & 55072 & -.04 & -.05 & .25 & -.37 & .26 & -.54 & .43 & 3 \\
\hline Conformity & 55 & 54959 & -.13 & -.17 & .20 & -.42 & .09 & -.56 & .23 & 4 \\
\hline Tradition & 51 & 53692 & -.18 & -.25 & .20 & -.51 & .01 & -.64 & .15 & 4 \\
\hline Security & 54 & 54377 & -.04 & -.05 & .17 & -.27 & .17 & -.39 & .29 & 6 \\
\hline
\end{tabular}

Note: $\mathrm{k}=$ number of studies; $\mathrm{N}=$ total number of individuals across all studies; Mean $\mathrm{r}=$ the average of the uncorrected correlations; $\rho=$ the estimated true score correlation; $\mathrm{SD}_{\mathrm{r}}=$ standard deviation of mean $\mathrm{r} ; \mathrm{SD}_{\rho}=$ the standard deviation of the corrected correlations; $\mathrm{CV}_{\mathrm{LL}}$ and $\mathrm{CV} \mathrm{UL}=$ lower and upper bounds, respectively, of the $80 \%$ credibility interval; $90 \% \mathrm{CV}=$ the $90 \%$ Credibility Value - this is the upper limit of the $80 \%$ credibility interval; $\mathrm{CI}_{\mathrm{LL}}$ and $\mathrm{CI}_{\mathrm{UL}}=$ lower and upper bounds, respectively, of the 95\% confidence interval around the corrected mean correlation; $\% \operatorname{Var}=$ the percentage of variance that was accounted for by statistical artifacts (sampling error and unreliability of measures). Bolded Mean $r$ values have a $95 \%$ confidence interval that does not include 0 . Bolded $\rho$ values have an $80 \%$ credibility interval that does not include 0 . 
Table 8

Meta-analytic Results for Conscientiousness and Values

\begin{tabular}{|c|c|c|c|c|c|c|c|c|c|c|}
\hline 10-factor Value Domains & $\mathbf{k}$ & $\mathbf{N}$ & Mean $\mathbf{r}$ & $\rho$ & SD $_{\rho}$ & $\mathrm{CV}_{\mathrm{LL}}$ & $\mathrm{CV}_{\mathrm{UL}}$ & $\mathbf{C I}_{\mathrm{LL}}$ & CIUL $_{\text {UL }}$ & $\%$ Var \\
\hline Power & 54 & 54599 & .04 & .05 & .09 & -.07 & .17 & -.13 & .23 & 17 \\
\hline Achievement & 55 & 54946 & .12 & .17 & .11 & .02 & .31 & -.05 & .39 & 12 \\
\hline Hedonism & 54 & 54391 & -.15 & -.19 & .15 & -.38 & .00 & -.49 & .11 & 6 \\
\hline Stimulation & 51 & 53692 & -.12 & -.16 & .18 & -.38 & .07 & -.50 & .19 & 5 \\
\hline Self-Direction & 55 & 54959 & .01 & .01 & .24 & -.29 & .31 & -.45 & .47 & 3 \\
\hline Universalism & 54 & 54364 & -.01 & -.02 & .18 & -.26 & .22 & -.38 & .35 & 4 \\
\hline Benevolence & 56 & 55072 & .05 & .07 & .16 & -.14 & .28 & -.25 & .39 & 6 \\
\hline Conformity & 55 & 54959 & .20 & .27 & .11 & .13 & .41 & .05 & .49 & 12 \\
\hline Tradition & 51 & 53692 & .07 & .10 & .12 & -.05 & .25 & -.13 & .33 & 13 \\
\hline Security & 54 & 54377 & .27 & .37 & .19 & .14 & .61 & .01 & .74 & 5 \\
\hline
\end{tabular}

Note: $\mathrm{k}=$ number of studies; $\mathrm{N}=$ total number of individuals across all studies; Mean $\mathrm{r}=$ the average of the uncorrected correlations; $\rho=$ the estimated true score correlation; $\mathrm{SD}_{\mathrm{r}}=$ standard deviation of mean $\mathrm{r} ; \mathrm{SD}_{\rho}=$ the standard deviation of the corrected correlations; $\mathrm{CV}_{\mathrm{LL}}$ and $\mathrm{CV} \mathrm{UL}_{\mathrm{UL}}=$ lower and upper bounds, respectively, of the $80 \%$ credibility interval; $90 \% \mathrm{CV}=$ the $90 \%$ Credibility Value - this is the upper limit of the $80 \%$ credibility interval; $\mathrm{CI}_{\mathrm{LL}}$ and $\mathrm{CI}_{\mathrm{UL}}=$ lower and upper bounds, respectively, of the 95\% confidence interval around the corrected mean correlation; $\% \operatorname{Var}=$ the percentage of variance that was accounted for by statistical artifacts (sampling error and unreliability of measures). Bolded Mean $r$ values have a $95 \%$ confidence interval that does not include 0 . Bolded $\rho$ values have an $80 \%$ credibility interval that does not include 0 . 
Table 9

Meta-analytic Results for Emotional Stability and Values

\begin{tabular}{|c|c|c|c|c|c|c|c|c|c|c|}
\hline 10-factor Value Domains & $\mathbf{k}$ & $\mathbf{N}$ & Mean $\mathbf{r}$ & $\rho$ & SD $_{\rho}$ & $\mathrm{CV}_{\mathrm{LL}}$ & $\mathrm{CV}_{\mathrm{UL}}$ & $\mathbf{C I}_{\text {LL }}$ & CIUL $_{\text {UL }}$ & \% Var \\
\hline Power & 52 & 54274 & .02 & .03 & .08 & -.07 & .13 & -.13 & .18 & 21 \\
\hline Achievement & 54 & 54747 & -.01 & -.01 & .10 & -.14 & .12 & -.21 & .19 & 14 \\
\hline Hedonism & 53 & 54165 & .01 & .01 & .05 & -.05 & .08 & -.09 & .12 & 35 \\
\hline Stimulation & 51 & 53692 & .01 & .02 & .13 & -.14 & .18 & -.23 & .27 & 9 \\
\hline Self-Direction & 55 & 54959 & -.01 & -.01 & .09 & -.13 & .11 & -.19 & .18 & 18 \\
\hline Universalism & 53 & 54165 & -.03 & -.03 & .07 & -.12 & .05 & -.16 & .10 & 25 \\
\hline Benevolence & 54 & 54747 & -.01 & -.01 & .10 & -.14 & .11 & -.20 & .18 & 14 \\
\hline Conformity & 55 & 54959 & -.04 & -.05 & .05 & -.12 & .01 & -.15 & .04 & 43 \\
\hline Tradition & 51 & 53692 & -.02 & -.03 & .04 & -.09 & .02 & -.12 & .05 & 53 \\
\hline Security & 54 & 54377 & -.02 & -.03 & .08 & -.13 & .07 & -.18 & .12 & 24 \\
\hline
\end{tabular}

Note: $\mathrm{k}=$ number of studies; $\mathrm{N}$ = total number of individuals across all studies; Mean $\mathrm{r}=$ the average of the uncorrected correlations; $\rho=$ the estimated true score correlation; $\mathrm{SD}_{\mathrm{r}}=$ standard deviation of mean $\mathrm{r} ; \mathrm{SD}_{\rho}=$ the standard deviation of the corrected correlations; $\mathrm{CV}_{\mathrm{LL}}$ and $\mathrm{CV} \mathrm{VL}_{\mathrm{UL}}=$ lower and upper bounds, respectively, of the $80 \%$ credibility interval; $90 \% \mathrm{CV}=$ the $90 \%$ Credibility Value - this is the upper limit of the $80 \%$ credibility interval; $\mathrm{CI}_{\mathrm{LL}}$ and $\mathrm{CI}_{\mathrm{UL}}=$ lower and upper bounds, respectively, of the 95\% confidence interval around the corrected mean correlation; $\% \operatorname{Var}=$ the percentage of variance that was accounted for by statistical artifacts (sampling error and unreliability of measures). Bolded Mean $r$ values have a $95 \%$ confidence interval that does not include 0 . Bolded $\rho$ values have an $80 \%$ credibility interval that does not include 0 . 
Table 10

Summary of the Main Meta-Analysis Results ( $\rho)$

\begin{tabular}{lccccc}
\hline & Openness to Experience & Agreeableness & Extraversion & Conscientiousness & Emotional Stability \\
\hline Power & -.06 & -.42 & .31 & .05 & .03 \\
Achievement & .11 & -.24 &. $\mathbf{3 1}$ &. $\mathbf{1 7}$ & -.01 \\
Hedonism & .09 & -.11 & .20 & -.19 & .01 \\
Stimulation & .36 & -.05 & .36 & -.16 & .02 \\
Self-Direction & .52 & -.07 & .17 & -.02 & -.01 \\
Universalism & .33 & .39 & -.05 & .07 & -.03 \\
Benevolence & .13 & .61 & -.05 & .27 & -.01 \\
Conformity & -.27 & .26 & -.17 & .10 & -.05 \\
Tradition & -.31 & .22 & -.25 & -.03 \\
Security & -.24 & .00 & -.05 & -.03 \\
\hline
\end{tabular}

Note: Generalizable results (in bold) refer to results for which the $80 \%$ credibility interval does not include 0 . 
Table 11

Personality and Values; Individualism/Collectivism of Culture as a Moderator

\begin{tabular}{|c|c|c|c|c|c|c|c|c|c|c|c|c|c|c|c|}
\hline & \multicolumn{3}{|c|}{ Openness to Experience } & \multicolumn{3}{|c|}{ Agreeableness } & \multicolumn{3}{|c|}{ Extraversion } & \multicolumn{3}{|c|}{ Conscientiousness } & \multicolumn{3}{|c|}{ Emotional Stability } \\
\hline & $\mathrm{k}$ & $\beta$ & $\mathrm{R}^{2}$ & $\mathrm{k}$ & $\beta$ & $\mathrm{R}^{2}$ & $\mathrm{k}$ & B & $\mathrm{R}^{2}$ & $\mathrm{k}$ & $\beta$ & $\mathrm{R}^{2}$ & $\mathrm{k}$ & $\beta$ & $\mathrm{R}^{2}$ \\
\hline Power & 44 & -.01 & .00 & 45 & .14 & .02 & 45 & -.09 & .01 & 45 & -.07 & .00 & 44 & .20 & .04 \\
\hline Achievement & 46 & .16 & .03 & 47 & .25 & $.06 \dagger$ & 47 & -.03 & .00 & 47 & .16 & .02 & 46 & .38 & $.14^{*}$ \\
\hline Hedonism & 45 & -.07 & .01 & 45 & .30 & $.09 *$ & 45 & -.04 & .00 & 46 & .14 & .02 & 45 & .21 & .04 \\
\hline Stimulation & 43 & -.13 & .02 & 43 & -.07 & .01 & 43 & -.03 & .00 & 45 & .06 & .00 & 43 & .34 & $.12 *$ \\
\hline Self-Direction & 47 & .14 & .02 & 47 & -.14 & .02 & 47 & -.05 & .00 & 47 & -.06 & .00 & 47 & .31 & $.10 *$ \\
\hline Universalism & 45 & .08 & .01 & 46 & -.04 & .00 & 46 & .08 & .01 & 46 & -.08 & .01 & 45 & -.03 & .00 \\
\hline Benevolence & 46 & -.01 & .00 & 47 & -.02 & .00 & 47 & .20 & .04 & 47 & .11 & .01 & 46 & -.16 & .02 \\
\hline Conformity & 47 & .00 & .00 & 47 & -.05 & .00 & 47 & .16 & .03 & 47 & .00 & .00 & 47 & -.09 & .01 \\
\hline Tradition & 43 & .08 & .01 & 43 & .19 & .03 & 43 & .10 & .01 & 43 & .14 & .02 & 43 & -.20 & .04 \\
\hline Security & 46 & .05 & .00 & 46 & .17 & .03 & 46 & .16 & .03 & 46 & .02 & .00 & 46 & -.01 & .00 \\
\hline
\end{tabular}

Note: $\mathrm{k}=$ the number of studies. $\beta=$ the standardized beta weight of the independent variable (individualism/collectivism).

$\dagger$ Significant at $\mathrm{p}<.10$.

* Significant at $\mathrm{p}<.05$. 
Table 12

Personality and Values; Tightness/Looseness of Culture as a Moderator

\begin{tabular}{|c|c|c|c|c|c|c|c|c|c|c|c|c|c|c|c|}
\hline & \multicolumn{3}{|c|}{ Openness to Experience } & \multicolumn{3}{|c|}{ Agreeableness } & \multicolumn{3}{|c|}{ Extraversion } & \multicolumn{3}{|c|}{ Conscientiousness } & \multicolumn{3}{|c|}{ Emotional Stability } \\
\hline & $\mathrm{k}$ & $\beta$ & $\mathrm{R}^{2}$ & $\mathrm{k}$ & $\beta$ & $\mathrm{R}^{2}$ & $\mathrm{k}$ & B & $\mathrm{R}^{2}$ & $\mathrm{k}$ & $\beta$ & $\mathrm{R}^{2}$ & $\mathrm{k}$ & $\beta$ & $\mathrm{R}^{2}$ \\
\hline Power & 42 & .14 & .02 & 43 & -.27 & $.07 \dagger$ & 43 & .06 & .00 & 43 & -.32 & $.10 *$ & 42 & .39 & $.15^{*}$ \\
\hline Achievement & 44 & -.01 & .00 & 45 & -.27 & $.07 \dagger$ & 45 & .22 & .05 & 45 & -.20 & .04 & 44 & -.01 & .00 \\
\hline Hedonism & 43 & .33 & $.11^{*}$ & 43 & -.29 & $.08 \dagger$ & 43 & .10 & .01 & 44 & -.24 & .06 & 43 & .11 & .01 \\
\hline Stimulation & 41 & .30 & $.09 \dagger$ & 41 & -.05 & .00 & 41 & .19 & .04 & 41 & .17 & .03 & 41 & .08 & .01 \\
\hline Self-Direction & 45 & .03 & .00 & 45 & .25 & .06 & 45 & .27 & $.07 \dagger$ & 45 & .22 & .05 & 45 & -.16 & .03 \\
\hline Universalism & 43 & -.01 & .00 & 44 & .40 & $.16^{*}$ & 44 & -.11 & .01 & 44 & .44 & $.19 *$ & 43 & -.06 & .00 \\
\hline Benevolence & 44 & .26 & $.07 \dagger$ & 45 & .21 & .05 & 45 & -.08 & .01 & 45 & .02 & .00 & 44 & -.17 & .03 \\
\hline Conformity & 45 & -.01 & .00 & 45 & -.16 & .03 & 45 & -.19 & .03 & 45 & -.14 & .02 & 45 & -.08 & .01 \\
\hline Tradition & 41 & -.19 & .04 & 41 & -.31 & $.09 \dagger$ & 41 & -.33 & $.11^{*}$ & 41 & -.14 & .02 & 41 & -.21 & .04 \\
\hline Security & 44 & -.11 & .01 & 44 & -.36 & $.13^{*}$ & 44 & -.17 & .03 & 44 & -.12 & .02 & 44 & .19 & .04 \\
\hline
\end{tabular}

Note: $\mathrm{k}=$ the number of studies. $\beta=$ the standardized beta weight of the independent variable (tightness/looseness of culture).

$\uparrow$ Significant at $\mathrm{p}<.10$.

* Significant at $\mathrm{p}<.05$. 
Table 13

Meta-analytic Rho (\& SD-rho) for Personality and Values; Values Measure as Moderator

\begin{tabular}{|c|c|c|c|c|c|c|c|c|c|c|c|c|c|c|c|c|c|c|c|c|c|c|c|c|c|}
\hline & \multicolumn{5}{|c|}{ Openness to Experience } & \multicolumn{5}{|c|}{ Agreeableness } & \multicolumn{5}{|c|}{ Extraversion } & \multicolumn{5}{|c|}{ Conscientiousness } & \multicolumn{5}{|c|}{ Emotional Stability } \\
\hline & \multicolumn{2}{|c|}{ SVS } & \multicolumn{2}{|c|}{ PVQ } & \multirow[b]{2}{*}{$\mathrm{z}$} & \multicolumn{2}{|c|}{ svs } & \multicolumn{2}{|c|}{ PVQ } & \multirow[b]{2}{*}{$\mathrm{z}$} & \multicolumn{2}{|c|}{ SVS } & \multicolumn{2}{|c|}{ PVQ } & \multirow[b]{2}{*}{$\mathrm{z}$} & \multicolumn{2}{|c|}{ SVS } & \multicolumn{2}{|c|}{ PVQ } & \multirow[b]{2}{*}{$\mathrm{z}$} & \multicolumn{2}{|c|}{ SVS } & \multicolumn{2}{|c|}{ PVQ } & \multirow[b]{2}{*}{$\mathrm{z}$} \\
\hline & $\rho$ & $\mathrm{SD} \rho$ & $\rho$ & $\mathrm{SD} \rho$ & & $\rho$ & $\mathrm{SD} \rho$ & $\rho$ & $\mathrm{SD} \rho$ & & $\rho$ & $\mathrm{SD} \rho$ & $\rho$ & $\mathrm{SD} \rho$ & & $\rho$ & $\mathrm{SD} \rho$ & $\rho$ & $\mathrm{SD} \rho$ & & $\rho$ & $\mathrm{SD} \rho$ & $\rho$ & $\mathrm{SD} \rho$ & \\
\hline Power & -.11 & .13 & -.03 & .06 & 2.82 & -.26 & .15 & -.53 & .17 & 5.56 & .14 & .10 & .43 & .07 & 11.8 & .06 & .09 & .05 & .09 & .37 & .05 & .06 & .01 & .08 & 1.82 \\
\hline Achievement & .13 & .15 & .11 & .06 & .63 & -.07 & .16 & -.36 & .21 & 5.02 & .20 & .12 & .39 & .15 & 4.55 & .22 & .09 & .12 & .11 & 3.24 & -.05 & .04 & .02 & .12 & 2.39 \\
\hline Hedonism & .08 & .05 & .09 & .14 & .29 & -.10 & .13 & -.12 & .08 & .64 & .14 & .06 & .25 & .08 & 4.97 & -.14 & .10 & -.22 & .17 & 1.81 & .03 & .05 & .01 & .06 & 1.17 \\
\hline Stimulation & .33 & .10 & .38 & .13 & 1.38 & -.03 & .12 & -.06 & .10 & .91 & .30 & .06 & .40 & .05 & 6.06 & -.08 & .05 & -.21 & .21 & 2.58 & -.10 & .05 & .10 & .10 & 7.86 \\
\hline Self-Direction & .51 & .12 & .54 & .09 & .98 & -.02 & .19 & -.10 & .19 & 1.40 & .12 & .14 & .19 & .18 & 1.41 & .04 & .14 & -.01 & .29 & .68 & -.08 & .05 & .05 & .07 & 6.87 \\
\hline Universalism & .37 & .09 & .30 & .10 & 2.39 & .29 & .11 & .45 & .07 & 6.03 & .06 & .12 & -.13 & .12 & 5.24 & .01 & .14 & -.03 & .21 & .71 & .01 & .04 & -.05 & .07 & 3.30 \\
\hline Benevolence & .10 & .11 & .16 & .10 & 1.91 & .46 & .16 & .71 & .06 & 7.70 & .12 & .12 & -.20 & .24 & 5.28 & .14 & .09 & .01 & .18 & 2.86 & -.03 & .05 & 0 & .12 & 1.01 \\
\hline Conformity & -.20 & .14 & -.32 & .15 & 2.73 & .28 & .09 & .26 & .10 & .69 & .01 & .10 & -.29 & .16 & 7.14 & .30 & .09 & .25 & .12 & 1.52 & -.05 & .03 & -.06 & .05 & .77 \\
\hline Tradition & -.22 & .11 & -.38 & .13 & 4.30 & .27 & .11 & .20 & .11 & 2.09 & -.07 & .10 & -.40 & .12 & 9.65 & .12 & .10 & .08 & .13 & 1.11 & -.03 & .04 & -.04 & .05 & .71 \\
\hline Security & -.17 & .17 & -.28 & .15 & 2.30 & .14 & .14 & -.09 & .12 & 5.94 & .08 & .13 & -.13 & .15 & 4.88 & .28 & .09 & .44 & .20 & 3.19 & .01 & .04 & -.06 & .07 & 3.86 \\
\hline Avg \% Varianc & 18 & & & & & 14 & & & & & 20 & & & & & 22 & & 5 & & & 55 & & & & \\
\hline
\end{tabular}

Note: Generalizable results (bolded $\rho$ ) refer to results for which the $80 \%$ credibility interval does not include 0 . SVS $=$ Schwartz Value Survey (Schwartz, 1992); PVQ = Portrait Values Questionnaire (Schwartz et al., 2001). Avg \% Variance = the average percent variance accounted for. The number of studies for the SVS ranged from 27-30 (N ranged from 19,276-20,183); for the PVQ there were 18 studies $(\mathrm{N}=32,707)$. The $\mathrm{z}$ test is used to test for whether the $95 \%$ confidence intervals overlap (Hunter \& Schmidt, 1990); $\mathrm{z}>$ 1.96 indicates that the scores are significantly different at $\mathrm{p}<=.05 ; \mathrm{z}>2.56$ indicates that the scores are significantly different at $\mathrm{p}<=$ .01 . 
Table 14

Meta-analytic Rho (\& SD-rho) for Personality and Values; Personality Measure as Moderator

\begin{tabular}{|c|c|c|c|c|c|c|c|c|c|c|c|c|c|c|c|c|c|c|c|c|c|c|c|c|c|}
\hline & \multicolumn{5}{|c|}{ Openness to Experience } & \multicolumn{5}{|c|}{ Agreeableness } & \multicolumn{5}{|c|}{ Extraversion } & \multicolumn{5}{|c|}{ Conscientiousness } & \multicolumn{5}{|c|}{ Emotional Stability } \\
\hline & \multicolumn{2}{|c|}{ BFI } & \multicolumn{2}{|c|}{ NEO } & \multirow[b]{2}{*}{$\mathrm{z}$} & \multicolumn{2}{|c|}{ BFI } & \multicolumn{2}{|c|}{ NEO } & \multirow[b]{2}{*}{$\mathrm{z}$} & \multicolumn{2}{|c|}{ BFI } & \multicolumn{2}{|c|}{ NEO } & \multirow[b]{2}{*}{$\mathrm{z}$} & \multicolumn{2}{|c|}{ BFI } & \multicolumn{2}{|c|}{ NEO } & \multirow[b]{2}{*}{$\mathrm{z}$} & \multicolumn{2}{|c|}{ BFI } & \multicolumn{2}{|c|}{ NEO } & \multirow[b]{2}{*}{$\mathrm{z}$} \\
\hline & $\rho$ & $\mathrm{SD} \rho$ & $\rho$ & $\mathrm{SD} \rho$ & & $\rho$ & $\mathrm{SD} \rho$ & $\rho$ & $\mathrm{SD} \rho$ & & $\rho$ & $\mathrm{SD} \rho$ & $\rho$ & $\mathrm{SD} \rho$ & & $\rho$ & $\mathrm{SD} \rho$ & $\rho$ & $\mathrm{SD} \rho$ & & $\rho$ & $\mathrm{SD} \rho$ & $\rho$ & $\mathrm{SD} \rho$ & \\
\hline Power & -.08 & .05 & -.14 & .20 & .83 & -.50 & .23 & -.46 & .05 & .63 & .33 & .13 & .09 & .02 & 6.77 & .09 & .04 & .04 & .11 & 1.24 & -.02 & .06 & .02 & .02 & 2.28 \\
\hline Achievement & .10 & .08 & -.05 & .14 & 3.05 & -.38 & .25 & -.14 & .15 & 2.93 & .27 & .05 & .10 & .08 & 5.94 & .18 & .08 & .16 & .09 & .56 & -.09 & .03 & -.06 & .02 & 2.94 \\
\hline Hedonism & .01 & .07 & .04 & .07 & 1.04 & -.14 & .05 & -.19 & .10 & 1.46 & .19 & .04 & .10 & .08 & 3.28 & -.29 & .09 & -.18 & .06 & 3.65 & -.02 & .04 & .05 & .03 & 4.90 \\
\hline Stimulation & .31 & .08 & .22 & .09 & 2.35 & -.08 & .07 & -.15 & .08 & 2.06 & .36 & .04 & .27 & .04 & 5.08 & -.25 & .16 & -.15 & .03 & 2.27 & .07 & .15 & -.11 & .02 & 4.42 \\
\hline Self-Direction & .52 & .08 & .39 & .11 & 3.29 & -.17 & .13 & -.13 & .07 & .98 & .11 & .08 & -.04 & .09 & 4.34 & -.11 & .19 & -.08 & .06 & .56 & .02 & .11 & -.03 & .05 & 1.51 \\
\hline Universalism & .33 & .05 & .39 & .08 & 2.10 & .39 & .04 & .21 & .10 & 5.39 & -.05 & .15 & -.07 & .04 & .48 & -.11 & .15 & -.12 & .11 & .19 & .01 & .00 & .03 & .04 & 1.58 \\
\hline Benevolence & .13 & .03 & .05 & .11 & 2.24 & .68 & .10 & .32 & .14 & 6.96 & -.15 & .30 & .01 & .08 & 1.90 & -.02 & .15 & .08 & .07 & 2.18 & .07 & .07 & -.04 & .06 & 4.13 \\
\hline Conformity & -.29 & .10 & -.32 & .11 & .70 & .31 & .04 & .22 & .12 & 2.39 & -.21 & .20 & -.09 & .06 & 2.13 & .30 & .04 & .25 & .05 & 2.71 & -.04 & .02 & -.04 & .00 & .00 \\
\hline Tradition & -.29 & .08 & -.28 & .08 & .28 & .30 & .05 & .21 & .11 & 2.19 & -.28 & .21 & -.12 & .10 & 2.41 & .14 & .05 & .04 & .07 & 3.56 & -.02 & .02 & -.02 & .00 & .00 \\
\hline Security & -.25 & .10 & -.33 & .06 & 2.48 & -.01 & .18 & -.03 & .00 & .42 & -.06 & .18 & -.02 & .06 & .78 & .50 & .14 & .17 & .09 & 7.14 & -.08 & .04 & .03 & .03 & 7.86 \\
\hline Avg \% Variance & & & & & & & & & & & & & & & & & & & & & & & 7 & & \\
\hline
\end{tabular}

Note: Generalizable results (bolded $\rho$ ) refer to results for which the $80 \%$ credibility interval does not include 0 . BFI $=$ Big Five Inventory (John, Donahue, \& Kentle, 1991); NEO = NEO-PI-R or NEO-FFI (Costa \& McCrae, 1992). Avg \% Variance = the average percent variance accounted for. Fourteen studies used the BFI $(\mathrm{N}=25,776)$; for the NEO the number of studies ranged from 8-11 ( $N$ ranged from 6,289-6,974). The $\mathrm{z}$ test is used to test for whether the 95\% confidence intervals overlap (Hunter \& Schmidt, 1990); $>$ 1.96 indicates that the scores are significantly different at $\mathrm{p}<=.05 ; \mathrm{z}>2.56$ indicates that the scores are significantly different at $\mathrm{p}<=$ .01 . 
Table 15

Meta-analytic Rho (\& SD-rho) for Personality and Values; Method as Moderator

\begin{tabular}{|c|c|c|c|c|c|c|c|c|c|c|c|c|c|c|c|c|c|c|c|c|c|c|c|c|c|}
\hline & \multicolumn{5}{|c|}{ Openness to Experience } & \multicolumn{5}{|c|}{ Agreeableness } & \multicolumn{5}{|c|}{ Extraversion } & \multicolumn{5}{|c|}{ Conscientiousness } & \multicolumn{5}{|c|}{ Emotional Stability } \\
\hline & \multicolumn{2}{|c|}{ Partialled } & \multicolumn{2}{|c|}{ Corr.s } & \multirow[b]{2}{*}{$\mathrm{z}$} & \multicolumn{2}{|c|}{ Partialled } & \multicolumn{2}{|c|}{ Corr.s } & \multirow[b]{2}{*}{$\mathrm{z}$} & \multicolumn{2}{|c|}{ Partialled } & \multicolumn{2}{|c|}{ Corr.s } & \multirow[b]{2}{*}{$\mathrm{z}$} & \multicolumn{2}{|c|}{ Partialled } & \multicolumn{2}{|c|}{ Corr.s } & \multirow[b]{2}{*}{$\mathrm{z}$} & \multicolumn{2}{|c|}{ Partialled } & \multicolumn{2}{|c|}{ Corr.s } & \multirow[b]{2}{*}{$\mathrm{z}$} \\
\hline & $\rho$ & $\mathrm{SD} \rho$ & $\rho$ & $\mathrm{SD} \rho$ & & $\rho$ & $\mathrm{SD} \rho$ & $\rho$ & $\mathrm{SD} \rho$ & & $\rho$ & $\mathrm{SD} \rho$ & $\rho$ & $\mathrm{SD} \rho$ & & $\rho$ & $\mathrm{SD} \rho$ & $\rho$ & $\mathrm{SD} \rho$ & & $\rho$ & $\mathrm{SD} \rho$ & $\rho$ & $\mathrm{SD} \rho$ & \\
\hline Power & -.10 & .12 & -.05 & .08 & 1.68 & -.57 & .18 & -.25 & .13 & 7.13 & .30 & .19 & .26 & .09 & 0.95 & .07 & .09 & .03 & .09 & 1.53 & -.03 & .08 & .07 & .03 & 5.78 \\
\hline Achievement & .03 & .11 & .17 & .07 & 5.36 & -.37 & .24 & -.12 & .14 & 4.57 & .21 & .13 & .34 & .10 & 3.96 & .14 & .07 & .19 & .16 & 1.34 & -.07 & .08 & .01 & .07 & 3.69 \\
\hline Hedonism & -.01 & .07 & .14 & .04 & 9.22 & -.16 & .08 & -.07 & .12 & 2.95 & .17 & .07 & .20 & .09 & 1.25 & -.27 & .11 & -.15 & .15 & 3.11 & 0 & .04 & .02 & .05 & 1.49 \\
\hline Stimulation & .28 & .08 & .39 & .09 & 4.31 & -.12 & .08 & .01 & .06 & 6.21 & .34 & .06 & .35 & .05 & 0.61 & -.27 & .13 & -.09 & .14 & 4.45 & .08 & .14 & -.08 & .06 & 5.09 \\
\hline Self-Direction & .46 & .10 & .55 & .09 & 3.31 & -.21 & .13 & .05 & .08 & 8.59 & .05 & .12 & .25 & .10 & 6.36 & -.16 & .14 & .14 & .15 & 7.17 & .05 & .08 & -.08 & .07 & 6.06 \\
\hline Universalism & .33 & .07 & .33 & .15 & 0 & .35 & .12 & .37 & .10 & 0.63 & -.12 & .08 & .07 & .14 & 5.55 & -.16 & .12 & .11 & .10 & 8.50 & 0 & .04 & -.03 & .05 & 2.23 \\
\hline Benevolence & .10 & .09 & .14 & .11 & 1.35 & .59 & .21 & .59 & .09 & 0 & -.21 & .21 & .16 & .15 & 7.26 & -.04 & .13 & .20 & .08 & 8.02 & .05 & .08 & -.07 & .06 & 5.94 \\
\hline Conformity & -.33 & .11 & -.18 & .16 & 3.74 & .27 & .09 & .27 & .12 & 0 & -.26 & .14 & .01 & .18 & 5.76 & .27 & .07 & .33 & .09 & 2.56 & -.04 & .05 & -.07 & .05 & 2.09 \\
\hline Tradition & -.32 & .09 & -.24 & .14 & 2.24 & .25 & .09 & .25 & .13 & 0 & -.32 & .18 & -.10 & .16 & 4.34 & .11 & .08 & .16 & .08 & 2.09 & -.02 & .03 & -.06 & .05 & 3.20 \\
\hline Security & -.30 & .11 & -.16 & .15 & 3.36 & -.09 & .10 & .15 & .13 & 7.07 & -.14 & .11 & .09 & .17 & 5.45 & .45 & .20 & .33 & .14 & 2.43 & -.06 & .09 & 0 & .06 & 2.75 \\
\hline Avg \% Va & & & & & & & & & & & & & & & & & & 16 & & & & & & & \\
\hline
\end{tabular}

Note: Generalizable results (bolded $\rho$ ) refer to results for which the $80 \%$ credibility interval does not include 0 . Partialled refers to studies that partialled out the mean value score; corr.s refers to studies that just provided the straight correlation. Avg \% Variance $=$ the average percent variance accounted for. There were 24-28 studies that clearly partialled out the mean value score ( $\mathrm{N}$ ranged from 26,761-28,015) and 21-22 studies that clearly reported a straight correlation ( $\mathrm{N}$ ranged from 15,698-15,910). The $\mathrm{z}$ test is used to test for whether the 95\% confidence intervals overlap (Hunter \& Schmidt, 1990); z $>1.96$ indicates that the scores are significantly different at $\mathrm{p}<=.05 ; \mathrm{z}>2.56$ indicates that the scores are significantly different at $\mathrm{p}<=.01$. 